\title{
The Energetics of El Niño and La Niña
}

\author{
Lisa Goddard* and S. George Philander \\ Program in Atmospheric and Oceanic Sciences, Princeton University, Princeton, New Jersey
}

(Manuscript received 13 January 1998, in final form 4 August 1999)

\begin{abstract}
Data from a realistic model of the ocean, forced with observed atmospheric conditions for the period 195392, are analyzed to determine the energetics of interannual variability in the tropical Pacific. The work done by the winds on the ocean, rather than generating kinetic energy, does work against pressure gradients and generates buoyancy power, which in turn is responsible for the rate of change of available potential energy (APE). This means interannual fluctuations in work done by the wind have a phase that leads variations in APE. Variations in the sea surface temperature (SST) of the eastern equatorial Pacific and in APE are highly correlated and in phase so that changes in the work done by the wind are precursors of El Niño. The wind does positive work on the ocean during the half cycle that starts with the peak of El Niño and continues into La Niña; it does negative work during the remaining half cycle.

The results corroborate the delayed oscillator mechanism that qualitatively describes the deterministic behavior of ENSO. In that paradigm, a thermocline perturbation appearing in the western equatorial Pacific affects the transition from one phase of ENSO to the next when that perturbation arrives in the eastern equatorial Pacific where it influences SST. The analysis of energetics indicates that the transition starts earlier, during La Niña, when the perturbation is still in the far western equatorial Pacific. Although the perturbation at that stage affects the thermal structure mainly in the thermocline, at depth, the associated currents are manifest at the surface and immediately affect work done by the wind. For the simulation presented here, the change in energy resulting from adjustment processes far outweighs that due to stochastic processes, such as intraseasonal wind bursts, at least during periods of successive El Niño and La Niña events.
\end{abstract}

\section{Introduction}

Although the dynamics of El Niño (and La Niña) have been studied extensively [see, e.g., Neelin et al. (1998) and references therein], little attention has been paid to the energetics of interannual variability in the tropical Pacific Ocean. The few brief discussions of El Niño energetics (Yamagata 1985; Hirst 1986) have only addressed the event growth. We present here the energetics of the full quasiperiodic fluctuation between El Niño and La Niña states, and the identification of air-sea interaction important to the evolution of El Niño-La Niña that has not been fully appreciated by previous studies.

Earlier studies treated El Niño as an episodic phenomenon. Precursors were sought: Cane and Zebiak

\footnotetext{
* Current affiliation: Experimental Climate Forecast Group, International Research Institute for Climate Prediction, Lamont-Doherty Earth Observatory of Columbia University, Palisades, New York.

Corresponding author address: Dr. Lisa Goddard, International Research Institute for Climate Prediction, Lamont-Doherty Earth Observatory of Columbia University, 61 Route 9W, Palisades, NY 10964.

E-mail: goddard@iri.ldgo.columbia.edu
}

(1985) pointed to anomalously high upper-ocean heat content, and Wyrtki (1975) watched for persistently strong trade winds that would inexplicably relax. Little attention was paid to La Niña, which was described as an "overshoot" of El Niño conditions as the Pacific Ocean adjusted back toward normal (Cane and Zebiak 1985). However, the indices used to identify El Niño episodes exhibit a distinct spectral peak near 4 yr (e.g., Rasmusson and Carpenter 1982; Jiang et al. 1995), suggesting that the phenomenon is part of a continuous oscillation, albeit an irregular one.

Since the 1980s the commonly accepted view of this coupled air-sea variability is that of a quasiperiodic oscillation between cold and warm extremes, for which the delayed oscillator (Schopf and Suarez 1988) has become the dynamical paradigm. In the delayed oscillator, as originally described by Suarez and Schopf (1988) and Schopf and Suarez (1988), SST anomalies in the eastern Pacific associated with either La Niña or El Niño initiate wind stress anomalies in the central Pacific that feed back positively to the SST anomalies mainly through wind-forced changes in the local, eastern equatorial, thermocline depth. The wind stress anomalies also induce thermocline anomalies in the western Pacific of the opposite sign to those in the east that are uncoupled from the surface and that are ex- 
pected to adjust in the tropical Pacific basin as Rossby and Kelvin waves. Thus, when the adjusting Rossby waves reflect from the western boundary as Kelvin waves and arrive in the east, they terminate the current extreme phase and initiate growth of the opposite phase. In short, SST anomalies in the east are influenced positively by local processes acting now and negatively by nonlocal processes that will not be realized until after some delay.

In spite of its general acceptance as a conceptual model, considerable debate has arisen over the degree to which the delayed oscillator operates in nature. Critics use nature's poor agreement with the details of this simple model to question the deterministic nature of the El Niño-La Niña cycle. Li and Clarke (1994) showed that although equatorial wind stress anomalies are highly correlated with ocean signals arriving at the western boundary a few months later, those western Pacific ocean signals are only weakly correlated with the anomalous wind stress 12-18 months later. However, Mantua and Battisti (1994) point out that such a low correlation would result if the delayed signals were efficient at terminating the current event but less so at initiating the next one.

We adopt a loose interpretation of the delayed oscillator, allowing for reconciliation with other studies that suggest the delayed oscillator is not a good model for the El Niño -La Niña cycle. For example, Kessler et al. (1995) and McPhaden (1999) point to the importance of atmospheric intraseasonal [Madden-Julian oscillation (MJO)] variability in forcing equatorial Kelvin waves that played an important role in El Niño events of the 1990s. Also, Picaut and Delcroix (1995) and Picaut et al. (1997), although they do not wholly discount the delayed oscillator, call for substantial modification of it, by giving primary importance to zonal SST advection, particularly of the $28^{\circ} \mathrm{C}$ isotherm in the western-central Pacific, in the initiation of El Niño events. These results are not necessarily at odds with the delayed oscillator mechanism; they merely imply that SST can change by more varied processes than upwelling on the anomalous temperature gradient of remotely forced thermocline anomalies. Surely, varying combinations of these processes lead to the uniqueness of each event's evolution. Our results are not inconsistent with these studies, but we do maintain that the ocean's memory of previous air-sea interaction exerts a strong influence on future variability. We show that during periods of active interannual variability when cold events follow warm events, and so on, the delayed oscillator is responsible for the deterministic nature of the variability. However, the delayed oscillator does run out of energy eventually, at which time stochastic forcing, such as the MJO, may be the only possible mechanism.

This study examines the energy balances as well as the temporal and spatial structures of the energetics terms important to interannual variability in the tropical Pacific Ocean. We focus on the ocean component of the coupled air-sea system because of its large inertia and thus potential memory of previous air-sea interaction. Hirst (1986) recognized that the ultimate energy source for a growing event comes from latent heating of the atmosphere, and that the growing energy of the atmosphere feeds energy into the ocean. The subsequent importance of energy gained by the ocean on evolution of the current event and genesis of the next event lies at the heart of the delayed oscillator debate.

Following our energetics analysis, one can compare the change in oceanic energy resulting from the redistribution of previously acquired energy with the change in oceanic energy due to the growth of new perturbations. What is evident in our results is that the adjusting perturbations influence the basinwide energy through air-sea interaction long before their associated temperature anomaly is realized at the surface. This again is not inconsistent with the delayed oscillator mechanism, which describes the ocean current anomaly of the adjusting thermocline perturbations (eastward for a warm, downwelling Kelvin signal). However, the original vision of the adjusting ocean signals was that they were completely uncoupled from the surface until arriving in the east, where the depth anomaly of the thermocline would be translated into SST anomalies via equatorial upwelling.

The results presented in this paper are based on data from an OGCM forced with observed atmospheric data. In section 2 we describe the model configuration and details of the simulation, which covers the period 195392. The kinetic and available potential energies of the simulated interannual fluctuations, and the terms in the energetics equations responsible for the fluctuations, are described first in section 3. Section 3 then focuses on the spatial and temporal details of the energetics for a specific case study: the period 1970-75, during which a full cycle, from La Niña to El Niño and back to La Niña, was completed. Section 4 summarizes the results.

\section{The model}

The model used for this analysis is the modular ocean model (MOM1) (Pacanowski et al. 1991) produced at Geophysical Fluid Dynamics Laboratory and based on the primitive-equation ocean model, developed by Bryan and Cox (1967), and described by Cox (1984). The domain is the Pacific Ocean between $45^{\circ} \mathrm{S}$ and $55^{\circ} \mathrm{N}$, bounded by walls on the poleward edges of the midlatitude gyres and by realistic coastlines to the east and west, and realistic bottom topography is given by a moderately smoothed version of the Scripps topography. The model resolution is $1^{\circ}$ in longitude and variable in latitude, with $13^{\circ}$ resolution within $10^{\circ}$ of the equator, in order to resolve equatorial waves; the latitudinal resolution increases to $1^{\circ}$ between $10^{\circ}$ and $30^{\circ} \mathrm{N}$ and $\mathrm{S}$, then remains $1^{\circ}$ poleward of $30^{\circ}$. There are 27 levels in the vertical with 10 in the top $100 \mathrm{~m}$ to better resolve the thermocline, and the maximum depth is $3830 \mathrm{~m}$. 
The tracer fields have zero flux through the lateral and bottom boundaries. Instead, sponge layers placed within the northern and southernmost $10^{\circ}$ of the domain damp the model temperature and salinity fields toward Levitus climatology using a latitude-dependent timescale of (2-40 days $)^{-1}$. The model calculates a full surface heat flux based on observed atmospheric conditions and model-diagnosed oceanic conditions, as described by Rosati and Miyakoda (1988). The source term for the salinity field is a linear damping of the sea surface salinity to Levitus (1982) climatology at the rate of (120 days) $)^{-1}$.

For vertical mixing of both tracers and momentum, the Pacanowski and Philander (1981) scheme was chosen. This Richardson number-dependent method results in less mixing for more stable local conditions. The surface momentum flux is given by the Pacanowski wind stress (Pacanowski 1987) parameterization, which uses the bulk aerodynamic formula, taking the surface wind vectors relative to the velocity of the ocean surface. This formulation is appropriate to the Tropics and especially near the equator where the surface currents can exceed speeds of $1 \mathrm{~m} \mathrm{~s}^{-1}$ (Gill 1983; Richardson and McKee 1984). A complete description of the model setup and parameters chosen for the simulation presented here are given in Goddard (1995).

Initially, the model was assigned zero currents and given temperature and salinity fields from Levitus monthly climatology. The atmospheric data-monthly mean surface winds, air temperature, relative humidity, and cloudiness-applied to the OGCM are from the Comprehensive Ocean-Atmosphere Data Set (COADS) Release 1 (Slutz et al. 1985) and Release 1a (updated post-1979 data). Surface conditions from the COADS climatology, based on the period 1951-79, were applied for $5 \mathrm{yr}$ to spin up the ocean. Beginning with year 1952, the full (annual cycle plus interannual perturbation) COADS atmosphere was applied. The model has been integrated for $40 \mathrm{yr}, 1953-92$, plus spinup. The monthly climatology of the model is based on the model years 1953-79, the approximate climatology period defined in the COADS data.

In order to establish the realism of the OGCM simulation, we compare the simulated and observed ocean fields. COADS contains sea surface temperature (SST) data, but this is not used in forcing the model. Because SST anomalies lead air temperature anomalies interannually (e.g., Battisti 1988), the observed air temperature used in the model's calculation of surface heat fluxes is not sufficient to produce the simulated SST anomalies. Therefore, comparing the OGCM's SST with COADS SST tests the consistency of the model with its forcing data. As shown in Fig. 1a, the correlation is $r=0.83$ between the observed and simulated SST anomaly in Niño- $3\left(5^{\circ} \mathrm{S}-5^{\circ} \mathrm{N} ; 90^{\circ}-150^{\circ} \mathrm{W}\right)$ after smoothing with a 3-month running mean filter $(r=0.77$ for monthly means, with no additional smoothing), well above the $99 \%$ confidence level for significance. The model fails to capture the full magnitude of warm events, a problem that is likely due to a thermocline that is somewhat more diffuse than observed. The model also exhibits occasional brief cold anomalies not present in the observations, such as after the $1965 \mathrm{El} \mathrm{Niño} \mathrm{and}$ before the 1982/83 El Niño. The phasing of the SST variability is correct, however, and in general, the model is able to reproduce the magnitude of warm and cold events. The map of anomaly correlations (Fig. 1b) based on $39 \mathrm{yr}$ of monthly mean SST anomalies shows statistically significant agreement, exceeding 99\% confidence where shaded, between the observations and simulations for most of the tropical Pacific region, except in the western Pacific where the variance of SST anomalies is low (Evans et al. 1998), perhaps below the level of observational error. Also, cloud forcing, which plays an important role in the surface heat fluxes over the western Pacific, was crudely prescribed in our simulation and may be partly to blame.

The model produces a discernible thermocline (Fig. 1c). However, like many ocean models that do not incorporate subsurface observations, the thermocline diffuses slowly as the integration proceeds. COADS does not contain any subsurface data with which to compare the simulation. Thus a monthly averaged "snapshot" is provided from the brief period of overlap between Tropical Ocean and Global Atmosphere (TOGA)-Tropical Atmosphere-Ocean (TAO) array buoy data and our simulation. Even at nearly 40 model years into the integration, the $20^{\circ} \mathrm{C}$ isotherm representing the core of the thermocline agrees well with the observed data along the equator (Fig. 1c), although the vertical gradient of temperature around $20^{\circ} \mathrm{C}$ is weaker than observed. Earlier, such as during the 1970-75 period to be examined later as a case study, the thermocline is tighter (not shown) although still not to the degree seen in recent TOGA-TAO data.

The OGCM also reproduces reasonable climatological mean oceanic fields. [See Goddard (1995) for figures of the time mean simulated thermal and dynamic fields.] The model has an equatorial undercurrent, that reaches a maximum time mean speed of $80 \mathrm{~cm} \mathrm{~s}^{-1}$ and varies seasonally in agreement with the literature (Philander et al. 1987). The climatological vertical velocity fields indicate strong upwelling along most of the equator, and downwelling off the equator with the strongest downwelling areas in the central-western Pacific.

\section{Results}

\section{a. Available potential energy}

As will be shown throughout this section, the most relevant energy quantity to El Niño-La Niña is the gravitational available potential energy (APE). The gravitational APE measures the energy potentially available to the system from a horizontal redistribution of mass (Lorenz 1955). Thus the portion of the oceanic mass 
contributing to the APE is defined relative to a reference state by separating out the time mean component of the potential density that is hydrostatically balanced and varying only with depth over the tropical Pacific region. That is,

$$
\rho(x, y, z ; t)=\hat{\rho}(z)+\tilde{\rho}(x, y, z ; t) .
$$

Following this notation, $\hat{\rho}(z)$ represents the reference state of the mass field, and $\tilde{\rho}(x, y, z ; t)$ represents the perturbations to that mass field including the structure of the mean state as well as interannual variability. Quantitative values for APE are then calculated following the formulation of Oort et al. (1989),

$$
A=-\frac{1}{2} \frac{\tilde{\rho}^{2}}{\mathcal{N}^{2}} .
$$

This equation describes energy contained in the vertical perturbations to the potential density field, by using the depth-dependent stability factor, $\mathcal{N}^{2}=-\hat{\rho}_{z} / g$, to weight the density variance. However, for purposes of discussion, an alternate but more conceptual form is adopted:

$$
A=\frac{h^{2}}{2 \mathcal{S}^{2}}=\frac{1}{2 \mathcal{S}^{2}}\left(\bar{h}^{2}+2 \bar{h} h^{\prime}+h^{\prime 2}\right) .
$$

This formulation is equivalent to Eq. (2), applied to an isopycnal or shallow-water model. Here the depth displacement $h$ (positive for downward displacements) of a constant density surface from its mean depth $H$ substitutes for the vertical perturbations to the density field; and $\mathcal{S}^{2}\left[=H /\left(g_{\text {red }} \rho_{0}\right)\right]$ accounts for the gravitational stability, where $g_{\text {red }}$ is the reduced gravity, and $\rho_{0}$ is the background density. The mass field in Eq. (3) has been further decomposed into a mean component $\bar{h}$ and a perturbation component $h^{\prime}$. Thus the constituent terms in Eq. (3) are interpreted as mean state energy $\left(A_{\mathrm{mm}}\right)$, mean perturbation energy $\left(A_{\mathrm{mp}}\right)$, and perturbation energy $\left(A_{\mathrm{pp}}\right)$.

Figure 2 illustrates how changes in the ocean's mass field, manifested as changes in thermocline slope along the equator, contribute to these terms during El Niño and La Niña events. The mean state energy, $A_{\mathrm{mm}}$, is necessarily positive, resulting from the mean east-west slope of the thermocline maintained by the mean zonal winds. The perturbation energy, $A_{\mathrm{pp}}$ is also always positive since it is proportional to the interannual variance of the mass field. The sign of $A_{\mathrm{mp}}$, on the other hand, depends on the placement of the interannual perturbations relative to the mean state perturbations. When SST is anomalously warm in the eastern equatorial Pacific, as during El Niño, the cause and consequence is a deeper than average thermocline in the east (i.e., $h^{\prime}>0, \vec{h}<$ 0 ), which contributes to a flatter mass field and consequently less oceanic APE. The opposite is true for La Niña.

The importance of the mean state to the character of El Niño and La Niña is well recognized (e.g., Battisti and Hirst 1989; Neelin et al. 1998). The structure of the mean state, including the air-sea interaction that establishes it (Dijkstra and Neelin 1995), is why deep (shallow) thermocline perturbations in the eastern equatorial Pacific result in warm (cold) SST anomalies. Thus it comes as no surprise that the mean state is also central to the interannual energetics. If there were no structure in the mean state (i.e., if the mean mass field were horizontally leveled), the location of thermocline perturbations would not matter, and $A_{\text {mp }}$ would be zero. The discussion will therefore highlight both the generation of perturbations (perturbation energy) and their adjustment against the mean state (mean perturbation energy), and how these processes relate to what is already known about El Niño and La Niña.

\section{b. The energetics of interannual variability}

Interannually, APE far outweighs kinetic energy (KE) for both perturbation energy (Fig. 3a) and mean perturbation energy (Fig. 3b). On large space and timescales it is not surprising that the APE should dominate. Averaged over the tropical Pacific (from $15^{\circ} \mathrm{S}$ to $15^{\circ} \mathrm{N}$ ), the APE of the mean state is about 15 times greater than the $\mathrm{KE}$, and it is still 7 times greater than the $\mathrm{KE}$ from $5^{\circ} \mathrm{S}$ to $5^{\circ} \mathrm{N}$, where the zonal flow and thus the $\mathrm{KE}$ density is greatest (Goddard 1995). Furthermore, Anderson and Moore (1989) showed that although the energy of free Kelvin waves is equipartitioned between $\mathrm{KE}$ and APE, that of Rossby waves is stored almost entirely as APE. Therefore, one should expect APE to play a more significant role in the energetics of El NiñoLa Niña. However, it was not expected that the KE should constitute only a few percent of the anomalous energy in the tropical Pacific.

As evidenced by Fig. 4, APE correlates highly with the SST variability that defines the phase and amplitude of El Niño and La Niña. Thus, the SST anomalies associated with El Niño and La Niña are just the surface manifestation of a change in oceanic energy occurring throughout the entire upper ocean in the tropical Pacific. Averaged over a narrow equatorial zone, $A_{\mathrm{mp}}$ varies in phase with the Niño-3 SST anomaly [i.e., the anomalous SST averaged over the Niño-3 region $\left(5^{\circ} \mathrm{S}-5^{\circ} \mathrm{N} ; 150^{\circ}-\right.$ $90^{\circ} \mathrm{W}$ ), hereafter referred to as SSTa], shown in Figs. $4 \mathrm{a}, \mathrm{c}$. Thermocline changes in the eastern-central Pacific are associated with local SST changes [e.g., McPhaden et al. (1998) and references therein], and these thermocline changes constitute the majority of $A_{\mathrm{mp}}$ near the equator since the mean thermocline depth in the western equatorial Pacific is close to the $\left(15^{\circ} \mathrm{S}-15^{\circ} \mathrm{N}\right)$ basin average. Because these thermocline changes in the east occur as part of a basinwide variation, which is largely in balance with the trade winds, it has proved difficult to separate out the portion of the subsurface variability that is not in balance with the winds, since the adjustment of mass along the equator happens at relatively short timescales (Neelin 1991). Considering the larger tropical region $\left(15^{\circ} \mathrm{S}-15^{\circ} \mathrm{N}\right), A_{\mathrm{mp}}$ still correlates highly 
(a)

SSTa (NINO3)

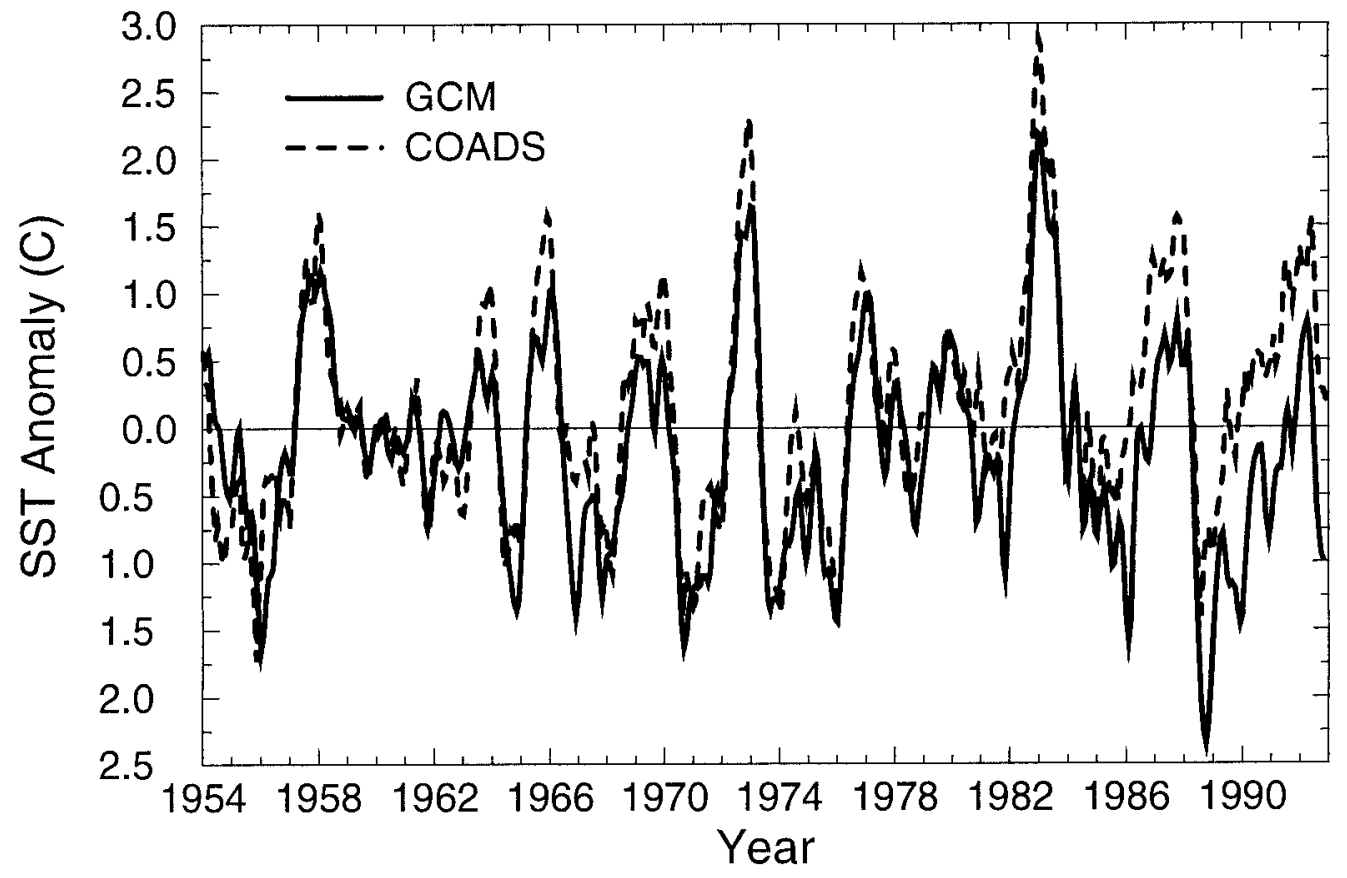

(b)

SST Anomaly Correlation (1953-1991)

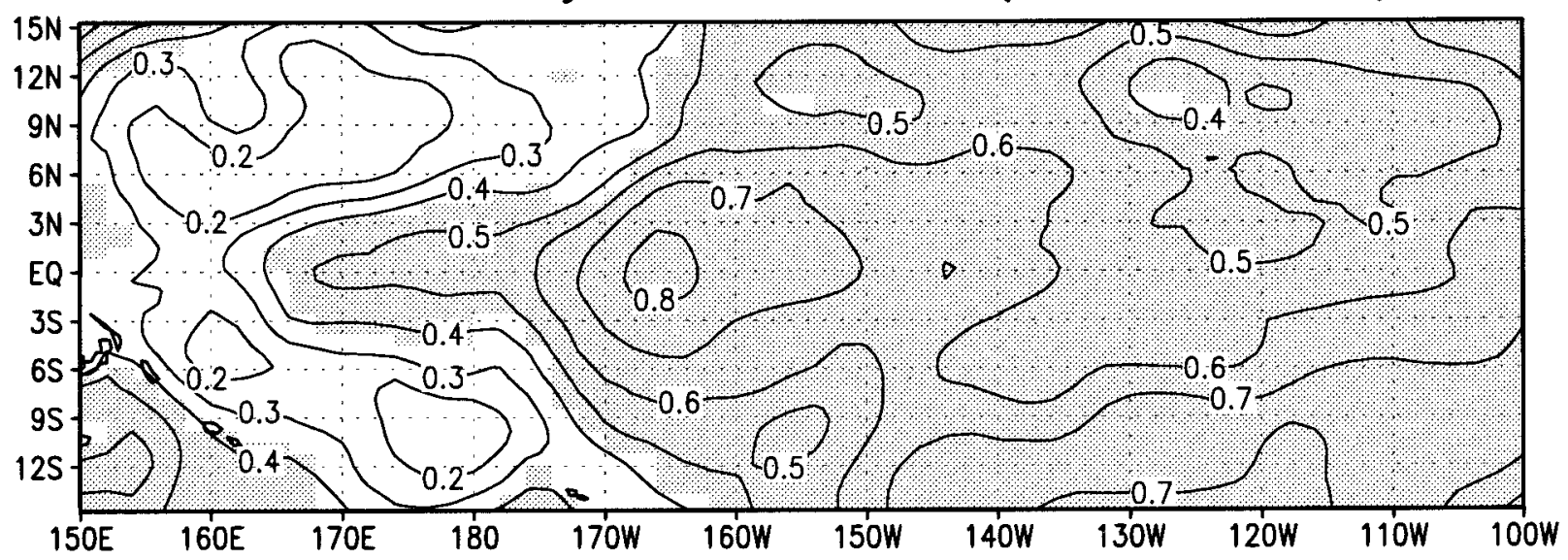

FIG. 1. (a) Time series of SST anomaly averaged over Niño-3 $\left(5^{\circ} \mathrm{S}-5^{\circ} \mathrm{N} ; 150^{\circ}-90^{\circ} \mathrm{W}\right)$ for GCM simulation (solid line) and COADS observations (dashed line), correlation between time series: $r=0.83$. Data have been smoothed with 3-month running mean filter $(r=0.77$ for unfiltered data). (b) Correlation map of GCM vs COADS anomalous monthly SST. Shading indicates statistically significant correlation

with SSTa (Fig. 4b) but now lags it by approximately 3 months (Fig. 4c), as seen in observations of sea level (McPhaden et al. 1998). Thus, once the warm (cold) event is underway, more energy is lost (gained) by the ocean off the equator, in the western Pacific (as will be shown later), in response to the anomalous winds associated with the event.

The in-phase relationship between SSTa and $A_{\mathrm{mp}}$ implies that the rate of change of the basinwide $A_{\mathrm{mp}}$ will lead SSTa. Balances of the energy equations are used to investigate whether there is a dominant term contributing to this change in APE, one that might be useful to monitor to anticipate future evolution of El Niño and La Niña events. The full form of the energy equations derived from the OGCM primitive equations is presented in appendix A. Here, only the distilled energy equations are discussed, those obtained from integrating the monthly mean energies over the tropical Pacific from 
(c)

\section{MODEL}

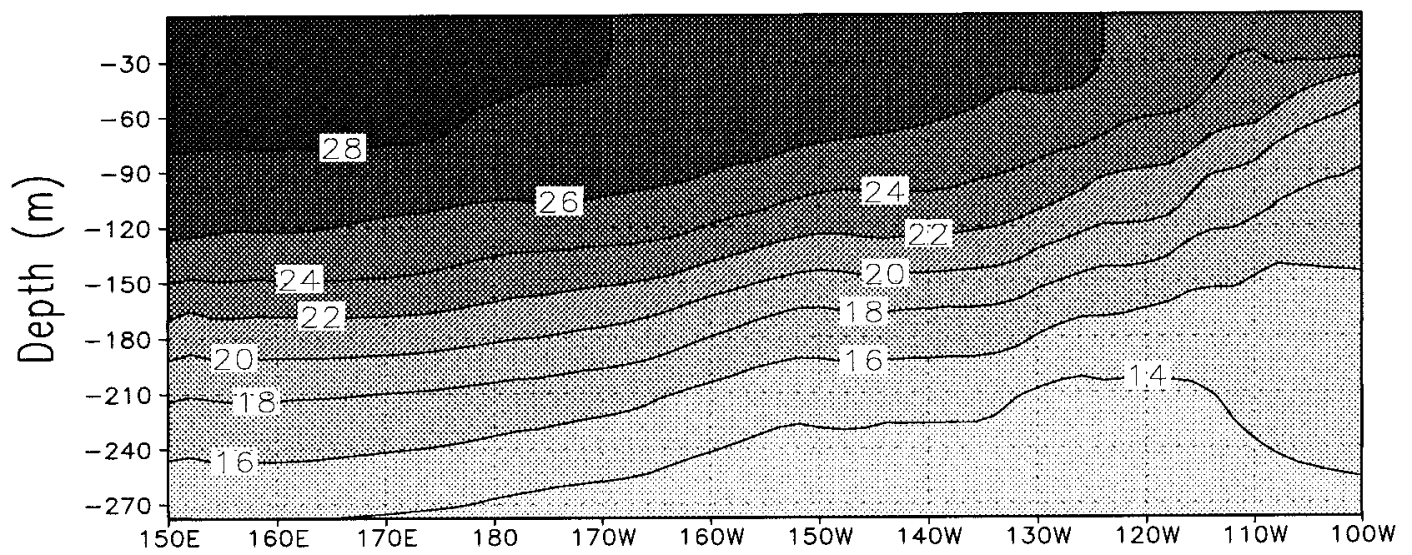

\section{TOGA-TAO}

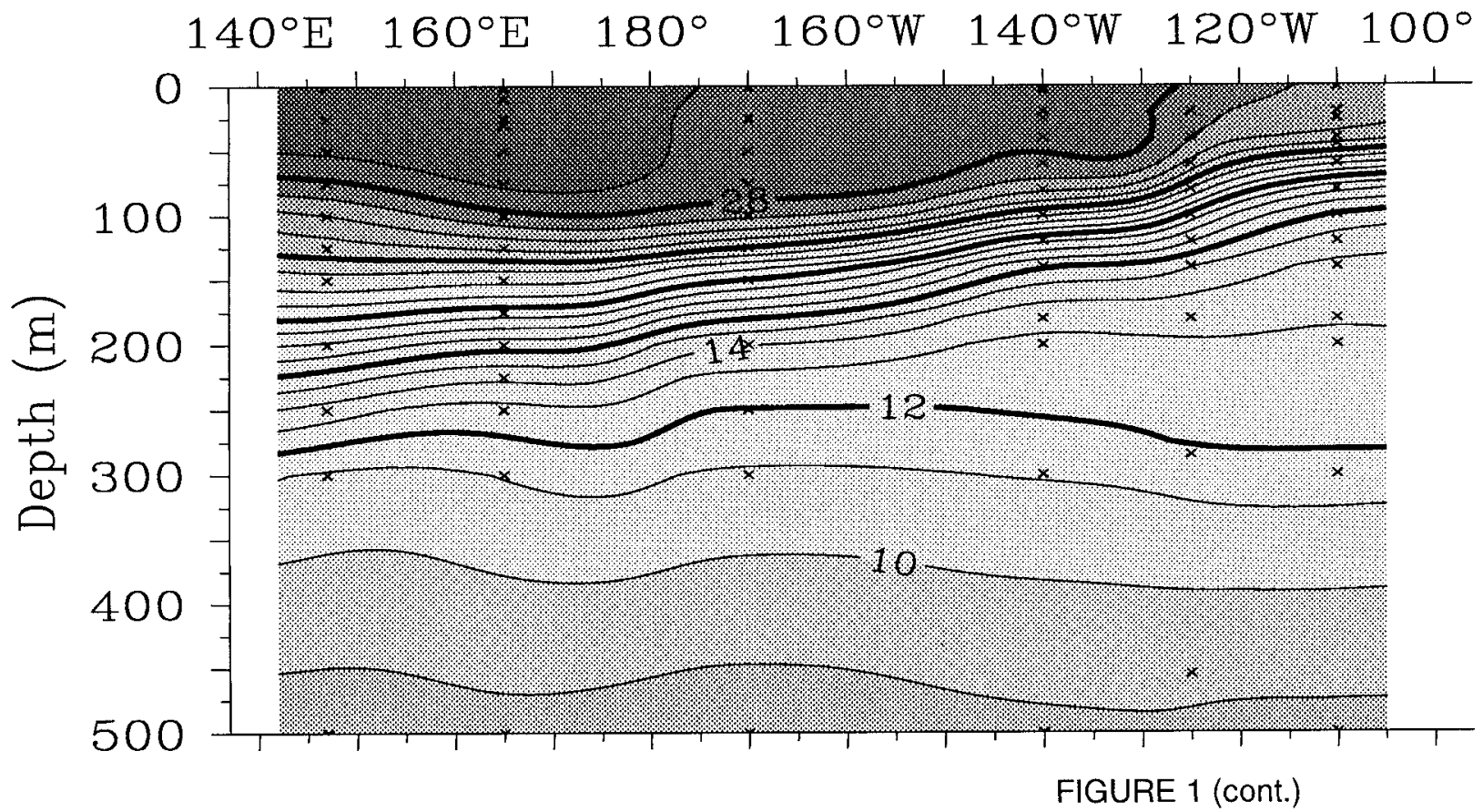

FIG. 1. (Continued) at the $99 \%$ confidence level. (c) Snapshot of longitude-depth thermal structure along equator for the month of Jun 1991 comparing total temperature field from GCM (top) to total temperatures from the TOGA-TAO observational buoy array (bottom).

$15^{\circ} \mathrm{S}$ to $15^{\circ} \mathrm{N}$, and to a depth of about $300 \mathrm{~m}$. The distilled equations will not always represent complete balance, but certainly the majority of it on this scale. Other terms in the full equations may yield substantial contributions locally that cancel when averaged over the larger domain.

The primary balance seen in the APE equation is

$$
\frac{\partial}{\partial t} \iiint A d V=g \iiint \tilde{\rho} w d V
$$

where $g$ is gravity, and $w$ is the vertical component of the oceanic velocity. The left-hand side is the rate of change of the volume integrated APE, and the righthand side is the vertical motion of the mass field, here called "buoyancy power" $[=-h w$, in the isopycnal notation of Eq. (3)]. This simple equation represents the main balance of energy for both the perturbation energy (Fig. 5a) and the mean perturbation energy (Fig. 6a). However, there are no external source or sink terms in Eq. (4), which merely describes a redistribution of mass. Heat fluxes through the surface, and flux convergence through the boundaries of the domain, are too small to affect the APE significantly and therefore do not appear in Eq. (4). Only on a few occasions, toward the end of 
some large events, does a sizable amount of energy flow through the eastern boundary of the integration domain.

The simplicity of Eq. (4) is its appeal. Obviously, one could examine, instead, the rate of change of SSTa, but in that case many processes are involved, such as upwelling in the presence of changing thermocline depth (e.g., Philander et al. 1984), anomalous zonal advection (e.g., Picaut and Delcroix 1995), and changes in airsea heat fluxes. The weakness of Eq. (4) is that upwelling is difficult to calculate from observations. However, data from high quality OGCMs forced with observed winds may be used as a surrogate (OCGMs that assimilate subsurface data lack consistency between their dynamical and thermodynamical fields).

The source term for the dynamical energy is found in the KE equation, where most terms in the full equation (A3) are again negligible on this basin-averaged scale. Thus, the primary balance of KE in the tropical Pacific Ocean on interannual timescales distills to

$$
\begin{aligned}
0 \approx & \iint_{z=0} \mathbf{v} \boldsymbol{\tau}_{o} d \sigma-\oint\left(\tilde{p}+p_{s}\right) \mathbf{u} \cdot \hat{n} d \sigma \\
& -g \iiint \tilde{\rho} w d V,
\end{aligned}
$$

where $\mathbf{v}$ represents the horizontal surface currents, $\boldsymbol{\tau}_{o}$ is the surface wind stress vector, $\tilde{p}$ is the portion of the oceanic pressure field not in hydrostatic balance with the reference density field [see Eq. (1)], $p_{s}$ is the atmospheric surface pressure, and $\mathbf{u}$ is the three-dimensional oceanic velocity field. The first term on the righthand side represents the work delivered by the atmosphere to the ocean, the second term is the work done against internal and surface pressure gradients by the ageostrophic flow, and the third term quantifies the work given to vertical motion of the mass field. As was seen in Eq. (4), the buoyancy power appears, but now with opposite sign, representing a conversion between $\mathrm{KE}$ and APE.

The balance shown in Eq. (5) is the energetics counterpart of the well-known momentum balance in which the winds primarily maintain pressure gradients. Using the $\mathrm{KE}$ equation instead of the momentum equations, however, it becomes possible to separate out the work done against pressure gradients, which is a relatively large quantity near the equator where the trade winds maintain the strong east-west slope in the thermocline. This leaves the buoyancy power, which quantifies the creation of thermocline perturbations through the horizontal convergence and divergence of the mass field. Using the kinetic energy equation also yields the explicit impact of the dynamical air-sea interaction by coupling the wind stress and ocean currents.

Whereas the momentum equations tell us that, at low frequencies, the winds maintain pressure gradients, the energy equations indicate that the wind, by doing work

\section{A.P.E. SCHEMATIC}
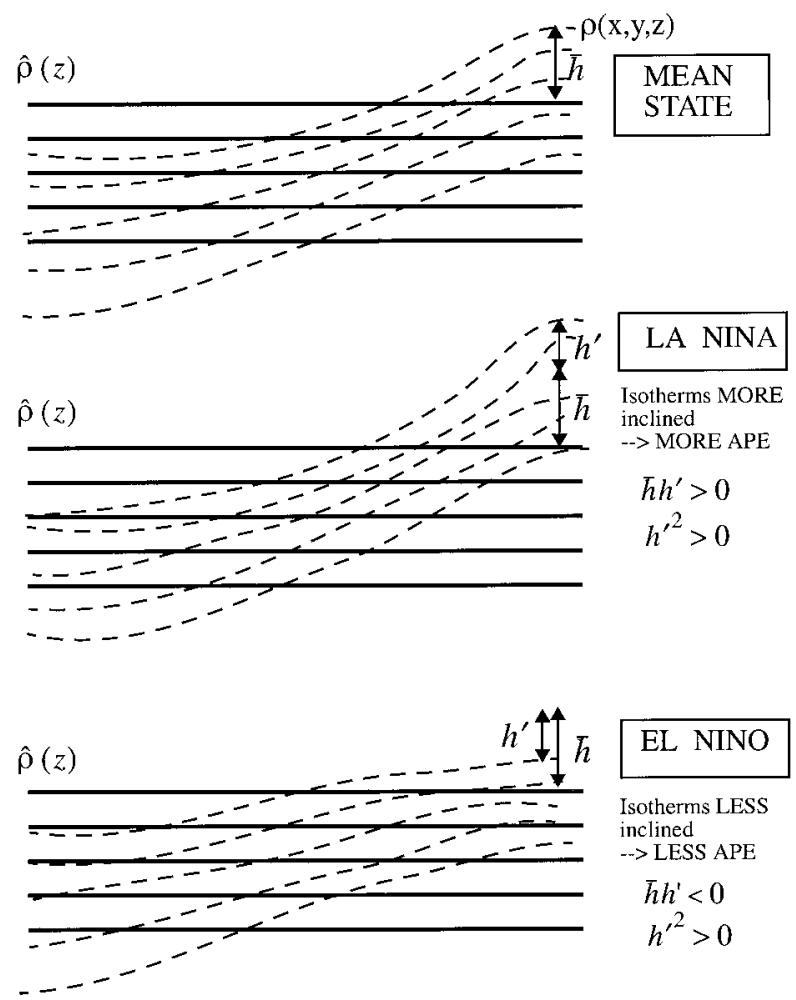

FIG. 2. Schematic of APE concept and how decomposition of APE is viewed. The top picture illustrates the mean state. Here $\bar{h}$ refers to the vertical deviation of the uppermost density surface from its horizontally averaged depth and is defined to be positive downward (note: $\bar{h}$ is therefore negative in the eastern Pacific, at the location indicated); $\bar{h}$ represents the mean climatological state and is the same for each sketch. Here $h^{\prime}$ is the interannual perturbation to $\bar{h}-0$ for the mean state, negative (positive) for La Niña (El Niño), in the eastern Pacific.

on the ocean, creates APE. Eqs. (4) and (5), written in terms of the perturbation energy, describe the creation and destruction of thermocline perturbations $\left(A_{\mathrm{pp}}\right)$. As shown in Fig. 5 (note that the buoyancy power is plotted in Figs. 5a,b with the sign as it appears in the APE equation), positive perturbation wind power,

$$
W_{\mathrm{pp}} \propto u^{\prime} \tau^{\prime},
$$

contributes positively to the perturbation buoyancy,

$$
B_{\mathrm{pp}} \propto-h^{\prime} w^{\prime},
$$

generating thermocline perturbations and increasing $A_{\mathrm{pp}}$. Thus oceanic energy grows while the $W_{\mathrm{pp}}$ is positive, consistent with the simple energetics analysis of Hirst (1986). Figure 5b further illustrates why the "tropical Pacific" region was chosen to extend to $15^{\circ} \mathrm{S}-15^{\circ} \mathrm{N}$; over this domain, the rate of ageostrophic pressure work is always seen as a sink of energy. Thus wind power is the only source of energy for the volume. The energy gained from $W_{\mathrm{pp}}$ eventually will be radiated out of the volume through the pressure power or dissipated by wave diffusion. 
(a)
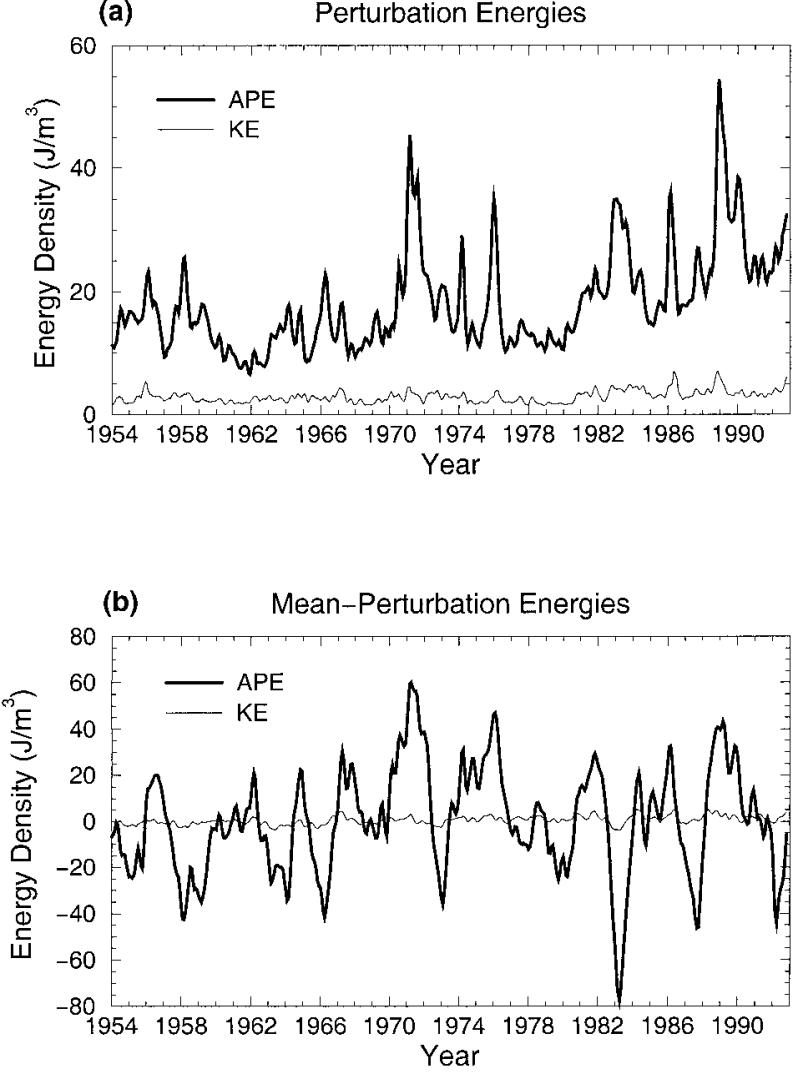

FIG. 3. (a) Perturbation available potential energy (heavy line) averaged over tropical Pacific Ocean $\left(15^{\circ} \mathrm{S}-15^{\circ} \mathrm{N} ; 150^{\circ} \mathrm{E}-100^{\circ} \mathrm{W} ; 30\right.$ $280 \mathrm{~m}$ ) and perturbation kinetic energy (light line) averaged over tropical Pacific Ocean $\left(15^{\circ} \mathrm{S}-15^{\circ} \mathrm{N} ; 150^{\circ} \mathrm{E}-100^{\circ} \mathrm{W} ; 0-280 \mathrm{~m}\right)$. (b) Same as in (a), except for the mean perturbation energy densities.

Once the perturbations are created, they can adjust within the basin, via equatorial wave dynamics. The signature of their adjustment can be seen in the mean perturbation energetics. The anomalous fields generated and/or maintained by $W_{\mathrm{pp}}$ do interact with the mean fields, and it is the temporal and spatial characteristics of this interaction that is meaningful for interannual variability in the tropical Pacific Ocean. As seen for the perturbation energetics, the time series for the mean perturbation energetics (Fig. 6) show a direct relationship between the mean perturbation wind power $\left(W_{\mathrm{mp}}\right)$ and the mean perturbation buoyancy power $\left(B_{\mathrm{mp}}\right)$. Both of these terms therefore relate directly to changes in $A_{\mathrm{mp}}$, and because of the close agreement between $A_{\mathrm{mp}}$ and SSTa, these terms may prove to be useful precursors to the termination and initiation of El Niño and La Niña events.

Comparing the mean perturbation energetics terms, $B_{\mathrm{mp}}$ and $W_{\mathrm{mp}}$ to their dynamics counterparts, upper-ocean heat content, and zonal wind stress (respectively), one finds that the energetics are indeed better indicators of future variability. Figure 7a shows the relationship between SSTa and $B_{\mathrm{mp}}$. The two time series exhibit peaks of similar shape and magnitude, with $B_{\mathrm{mp}}$ leading by approximately 3 months (Fig. 7c). The anomalous up- per-ocean heat content (e.g., Cane and Zebiak 1985), equivalent to the mass anomaly, also shows agreement with the SSTa (Fig. 7b), and the correlation between them does have a peak at 3-month lead. However, the correlation of SSTa with $B_{\mathrm{mp}}$ is significantly larger at this lead time. The mass anomaly actually correlates to SSTa slightly better at lag times of about 12 months (although the difference is not significant), suggesting that anomalous heat content is more a reaction to the El Niño-La Niña event than a cause.

As was just shown for the buoyancy power, $W_{\mathrm{mp}}$ represents a more reliable precursor of El Niño-La Niña evolution than does the zonal wind stress anomaly $\left(\tau^{x^{\prime}}\right)$ originally proposed by Wyrtki (1975). The correlation between the dynamical variables peaks at $r=0.4$ when $\tau^{x^{\prime}}$ is in phase with SSTa (Figs. 8b,c). The negative correlation Wyrtki referred to, where stronger easterlies precede warm SSTa by 1-2 yr, is weak and insignificant. To his credit, he does acknowledge that not all El Niños follow such sustained periods of intensified trade winds as occurred before the 1957/58 and 1972/73 El Niños (Wyrtki 1975).

The $W_{\mathrm{mp}}$ time series correlates with SSTa at better than $r=0.4$ for lead times up to 9 months, on average (Figs. 8a,c). Eventually the correlation peaks at $r=0.7$ with $W_{\mathrm{mp}}$ leading SSTa by about 2 months. It should be noted that Wyrtki's region of interest was restricted to $4^{\circ} \mathrm{S}-4^{\circ} \mathrm{N}$ and $180^{\circ}-140^{\circ} \mathrm{W}$, and in that case he obtained a much stronger relationship between $\tau^{x^{\prime}}$ and SSTa, but over that region the correlation for $W_{\mathrm{mp}}$ increases significantly too $(r=0.9)$ and still exceeds that of the wind stress anomaly. The peaks in the time-lagged correlations of both Figs. 7 and 8 at lead/lag times greater than 18 months merely reflect the quasiperiodic nature of El Niño-La Niña and are therefore not useful as precursors.

\section{c. Case study: 1970-75}

With the energetics of interannual variability presented and its relevance to the El Niño-La Niña cycle demonstrated, we now look in detail at a complete cycle of variability in the tropical Pacific. The years 1970 to 1975 saw a large-amplitude El Niño event in 1972, preceded and followed by La Niña events. The time series for SSTa, $A_{\mathrm{mp}}$, and $A_{\mathrm{pp}}$ (Fig. 9) exemplifies much of the previous discussion for a clearly identified sequence of El Niño and La Niña events: first, $A_{\mathrm{mp}}$ has a strong negative correlation with SSTa; and second, $A_{\mathrm{pp}}$ grows during the mature phase of an El Niño or La Niña event. Note, that the magnitude of $A_{\mathrm{mp}}$ is comparable to, but generally larger than, that of $A_{\mathrm{pp}}$, such that the total anomalous oceanic APE is positive during La Niña and negative during El Niño, as was illustrated schematically in Fig. 2.

By examining the timing, location, and processes by which the ocean gains energy and redistributes it, theories or paradigms such as the delayed oscillator can be tested. Treating first the perturbation energy, a series of maps are presented at selected points through the 1970- 
(a)

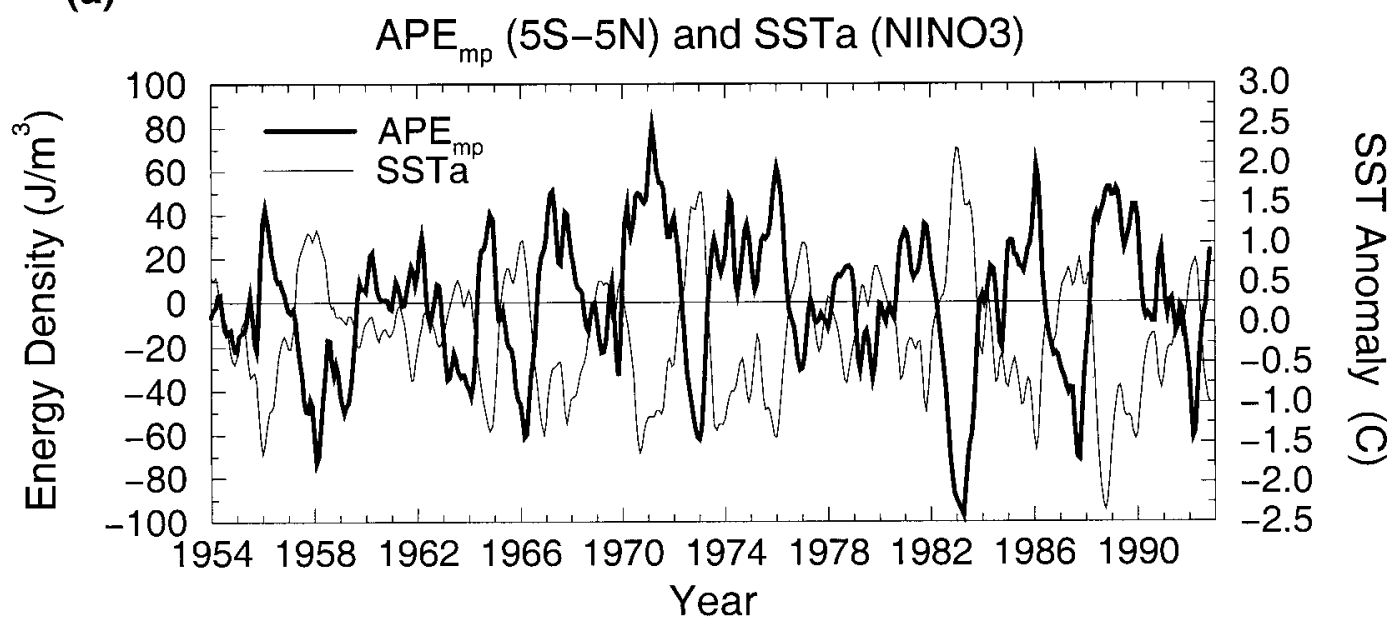

(b)
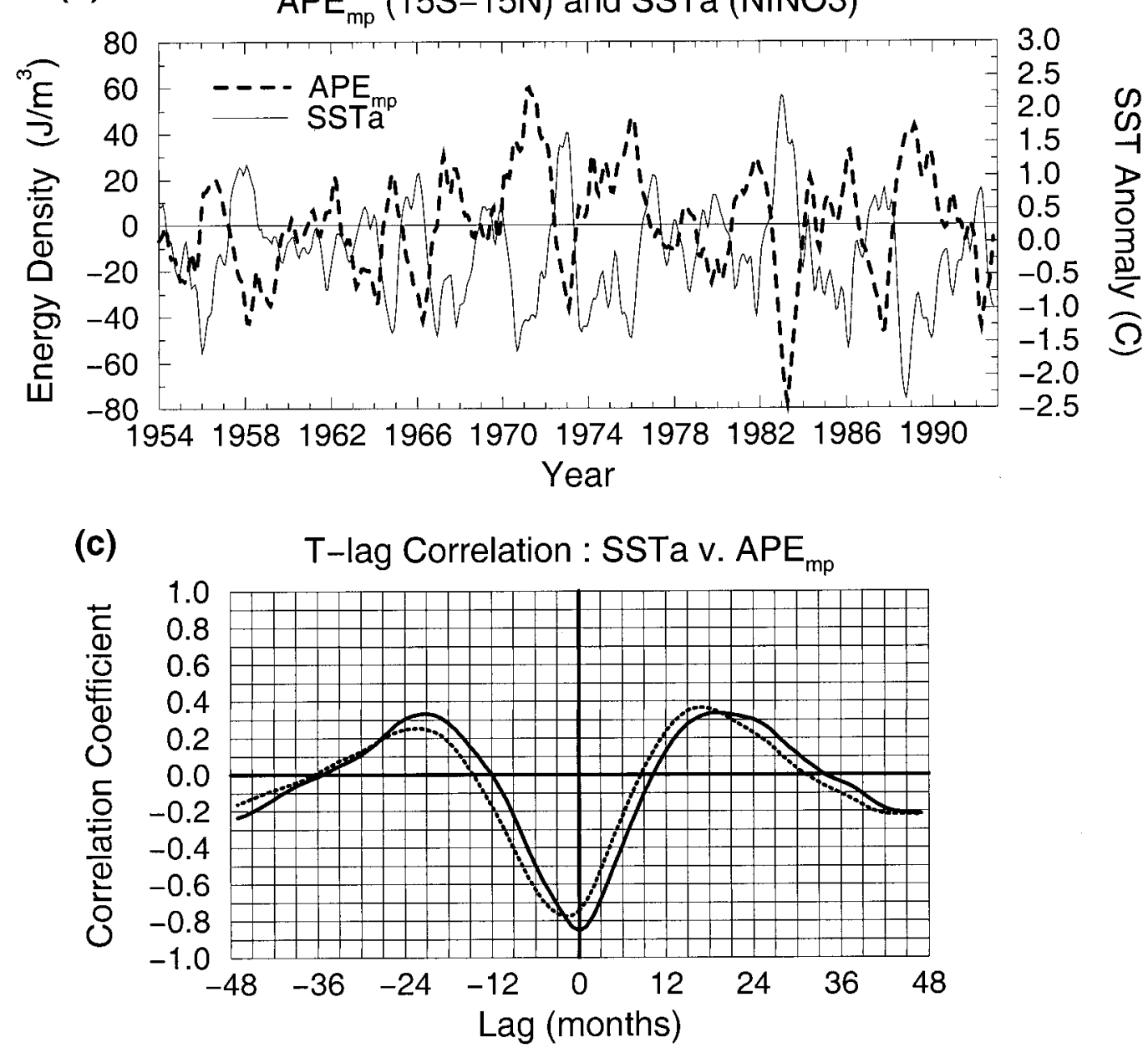

FIG. 4. (a) Mean perturbation APE averaged over equatorial Pacific Ocean $\left(5^{\circ} \mathrm{S}-5^{\circ} \mathrm{N} ; 150^{\circ} \mathrm{E}-100^{\circ} \mathrm{W} ; 30-280 \mathrm{~m}\right)$, and SST anomaly averaged over Niño-3 region $\left(5^{\circ} \mathrm{S}-5^{\circ} \mathrm{N} ; 150^{\circ}-90^{\circ} \mathrm{W}\right)$. (b) Same as (a), except energy is averaged over $\left(15^{\circ} \mathrm{S}-15^{\circ} \mathrm{N} ; 150^{\circ} \mathrm{E}-100^{\circ} \mathrm{W} ; 30-280 \mathrm{~m}\right)$. (c) Time-lag correlations between SSTa and $A_{\mathrm{mp}}$; SSTa lags $A_{\mathrm{mp}}$ for positive lag values. (Solid line: $A_{\mathrm{mp}}$ averaged $5^{\circ} \mathrm{S}-5^{\circ} \mathrm{N}$; dashed line: $A_{\mathrm{mp}}$ averaged $15^{\circ} \mathrm{S}-15^{\circ} \mathrm{N}$.) 
(a)

Primary Balance of Perturbation APE

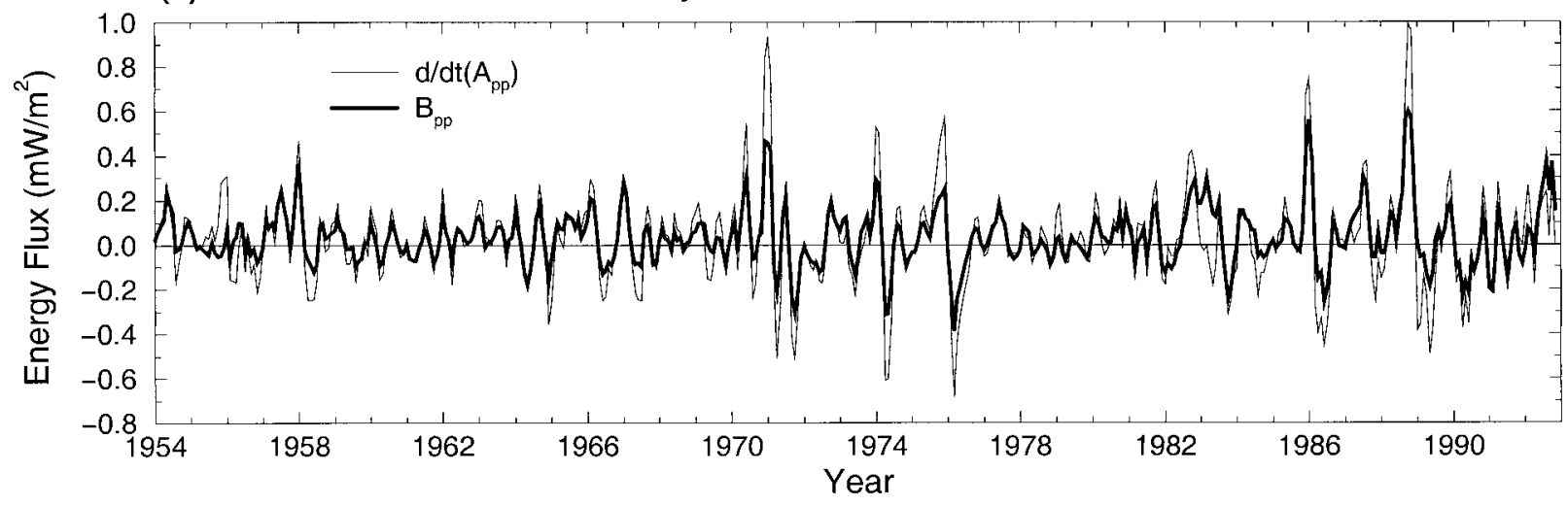

(b)

Primary Balance of Perturbation KE

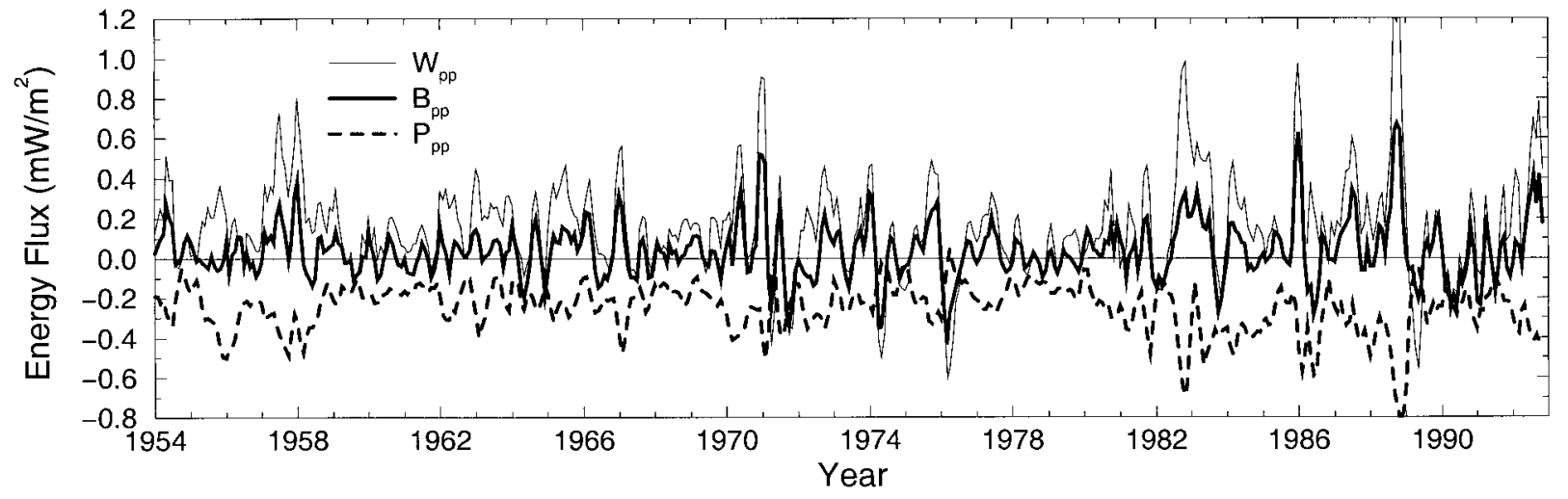

FIG. 5. (a) Primary balance of perturbation APE equation, averaged over subsurface tropical Pacific Ocean $\left(15^{\circ} \mathrm{S}-15^{\circ} \mathrm{N} ; 150^{\circ} \mathrm{E}-100^{\circ} \mathrm{W}\right.$; 30-280 m), showing rate of change of perturbation APE (light line) and perturbation buoyancy power, $B_{\mathrm{pp}}$ (heavy line). (b) Primary balance of perturbation KE equation, averaged over tropical Pacific Ocean $\left(15^{\circ} \mathrm{S}-15^{\circ} \mathrm{N} ; 150^{\circ} \mathrm{E}-100^{\circ} \mathrm{W} ; 0-280 \mathrm{~m}\right)$, showing rate of perturbation wind power, $W_{\mathrm{pp}}$ (light line); perturbation buoyancy power, $B_{\mathrm{pp}}$ (heavy solid line); and perturbation pressure power, $P_{\mathrm{pp}}$ (heavy dashed line).

75 period indicated by the $\times$ s on Fig. 9a. The previous discussion has shown that energy is gained during the mature phase of the event and provided by the wind power [as theorized by Yamagata (1985) and Hirst (1986)]. The structure of $B_{\mathrm{pp}}$ generated by $W_{\mathrm{pp}}$ agrees with the simple models that show thermocline reaction to zonal wind anomalies in the central basin (e.g., McCreary 1978). Thus, the large-scale easterly wind anomaly in December 1970 accelerated westward surface currents and fed energy into the ocean (Fig. 10a, left). Positive $B_{\mathrm{pp}}$ occurred off the flanks of $W_{\mathrm{pp}}$ (Fig. $10 \mathrm{a}$, right), with anomalous upwelling and a shoaling thermocline on the equator to the east, and downwelling and a deepening thermocline off the equator to the west. All these features are common to the discussions of the delayed oscillator (e.g., Schopf and Suarez 1988; Battisti 1988). Although sizable cold SST anomalies continued though 1971, the wind power did not (Fig. 10b, left). Thus, inconsistent with many theoretical and idealized discussions of the delayed oscillator model, the wind stress, and thus the wind power, are not smoothly varying at the low frequency displayed in the SSTa time series.
As the wind power weakens or disappears, the portion of the mass field that is no longer balanced by the largescale wind stress will adjust via equatorial wave dynamics-westward off the equator (Rossby waves) and eastward on the equator (Kelvin waves). The $B_{\mathrm{pp}}$ map suggests movement of thermocline perturbations (Fig. $10 \mathrm{~b}$, right), as perturbations gained between $160^{\circ} \mathrm{E}$ and $160^{\circ} \mathrm{W}$ (Fig. 10a, right) propagate toward the western boundary. Mere translation of perturbations will not affect the basinwide energy; as one region loses $A_{\mathrm{pp}}$, another gains it. However, when perturbations of opposite sign meet, such as when adjusting perturbations originally from the western Pacific arrive in the eastern equatorial Pacific, they can cancel each other, and net destruction of $A_{\mathrm{pp}}$ occurs. As adjusting thermocline perturbations begin to arrive in the east during late 1971/ early $1972, A_{\mathrm{pp}}$ decreases rapidly. During the early stage of development of the 1972/73 El Niño, some areas of $W_{\text {pp }}$ appear (Fig. 10c, left), particularly in the western Pacific, but they do not contribute to the growth of $A_{\mathrm{pp}}$, which continues to decrease at this time. It appears that some $A_{\mathrm{pp}}$ remains after the adjustment of perturbations 
(a)

Primary Balance of Mean-Perturbation APE

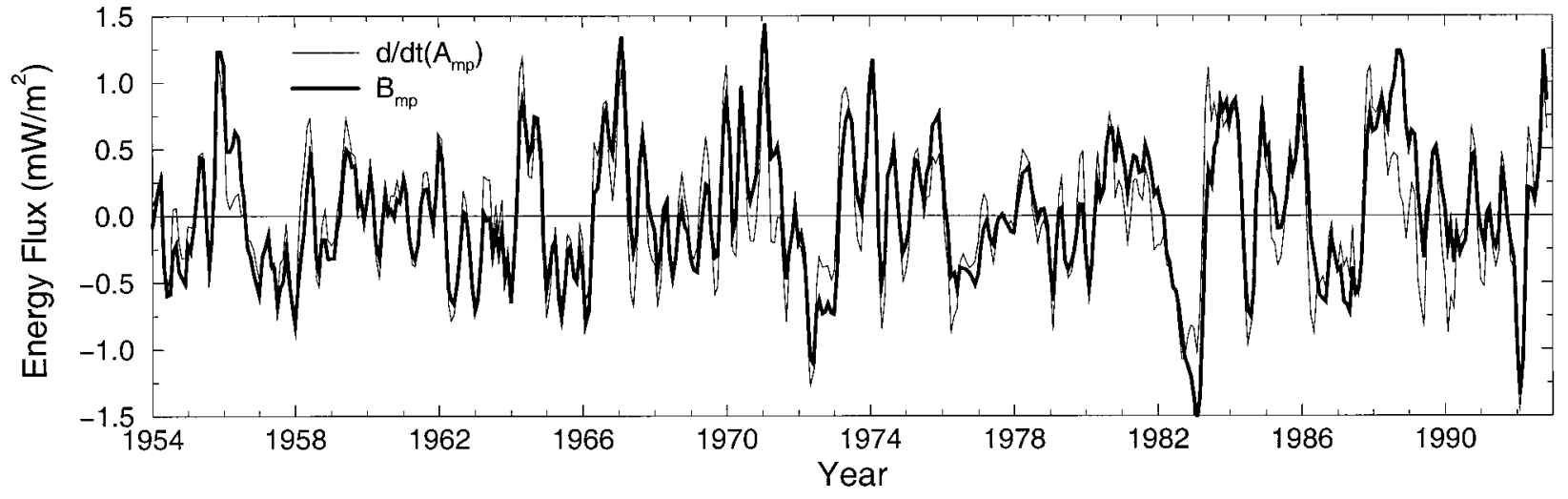

(b)

Primary Balance of Mean-Perturbation KE

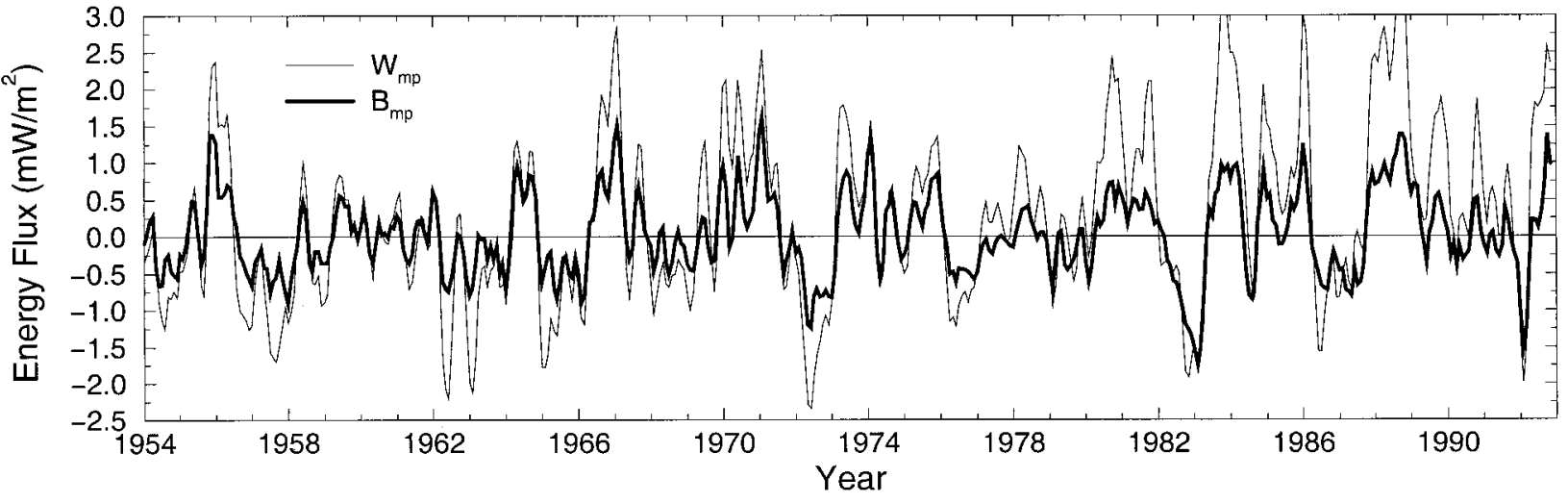

FIG. 6. (a) Primary balance of mean perturbation APE equation, averaged over subsurface tropical Pacific Ocean $\left(15^{\circ} \mathrm{S}-15^{\circ} \mathrm{N} ; 150^{\circ} \mathrm{E}-\right.$ $100^{\circ} \mathrm{W} ; 30-280 \mathrm{~m}$ ), showing rate of change of mean perturbation APE (light line) and mean perturbation buoyancy power, $B_{\mathrm{mp}}$ (heavy line). (b) Primary balance of mean perturbation KE equation, averaged over tropical Pacific Ocean $\left(15^{\circ} \mathrm{S}-15^{\circ} \mathrm{N} ; 150^{\circ} \mathrm{E}-100^{\circ} \mathrm{W} ; 0-280 \mathrm{~m}\right)$, showing rate of mean perturbation wind power, $W_{\mathrm{mp}}$ (light line) and mean perturbation buoyancy power, $B_{\mathrm{mp}}$ (heavy line).

generated during the 1970/71 La Niña (Fig. 9b), in the form of a deepened thermocline in the east (not shown), leading to warm SSTa and the start of the $1972 / 73 \mathrm{El}$ Niño. At the peak of the $1972 / 73$ El Niño $A_{\mathrm{pp}}$ is again delivered to the ocean (Figs. 9b, 10d,e), which is then depleted during the transition to La Niña conditions in mid-1973 (Fig. 9b). And again, residual energy exists in the ocean as the 1973/74 La Niña begins to grow. Notice, at the end of the $1973 / 74$ La Niña, $A_{\mathrm{pp}}$ is near zero, and another El Niño did not occur until 1976.

The important issue is to what degree the perturbation energy gained during one phase (El Niño or La Niña) impacts future variability. It is now well accepted that subsurface "memory" (i.e., the perturbation energy) does influence the subsequent evolution of the tropical Pacific [see Neelin et al. (1998) and references therein]. However, recent works (Kessler et al. 1995; McPhaden 1999) have suggested a more important role for nondeterministic forcing, such as intraseasonal westerly wind bursts and the Madden-Julian oscillation. The relative contributions of all these processes is certain to vary from one event to the next. An examination of the mean perturbation energetics potentially can ascertain which mechanism dominates, in general or for a specific period.

The mean perturbation buoyancy power, $B_{\mathrm{mp}}$, contributes directly to changes in $A_{\mathrm{mp}}$ [Eq. (4); Fig. 6], which mirror changes in SSTa (Figs. 4 and 9). When decomposed, it is evident that $B_{\mathrm{mp}}$ is affected by two processes:

$$
B_{\mathrm{mp}} \propto-h^{\prime} \bar{w}-\bar{h} w^{\prime},
$$

where, as described in Fig. 2, $h$ is defined positive downward. The adjustment of existing thermocline perturbations dominates the first term on the right, which will be called "adjustment buoyancy." The spontaneous action of the wind initiating areas of anomalous upwelling dominates the second term, which will be called "wind-driven buoyancy." Figure 11 illustrates schematically how both these terms contribute to changes in $A_{\mathrm{mp}}$ for the case of a shallow, upwelling perturbation freely propagating eastward along the equatorial thermocline. Assuming that $w^{\prime}$ $<\bar{w}$ and $h^{\prime} \approx \bar{h}, h^{\prime} \bar{w}$ will monopolize $B_{\mathrm{mp}}$ in the ad- 
(a) Anomalous Buoyancy Power (5S-5N) and SSTa (NINO3)

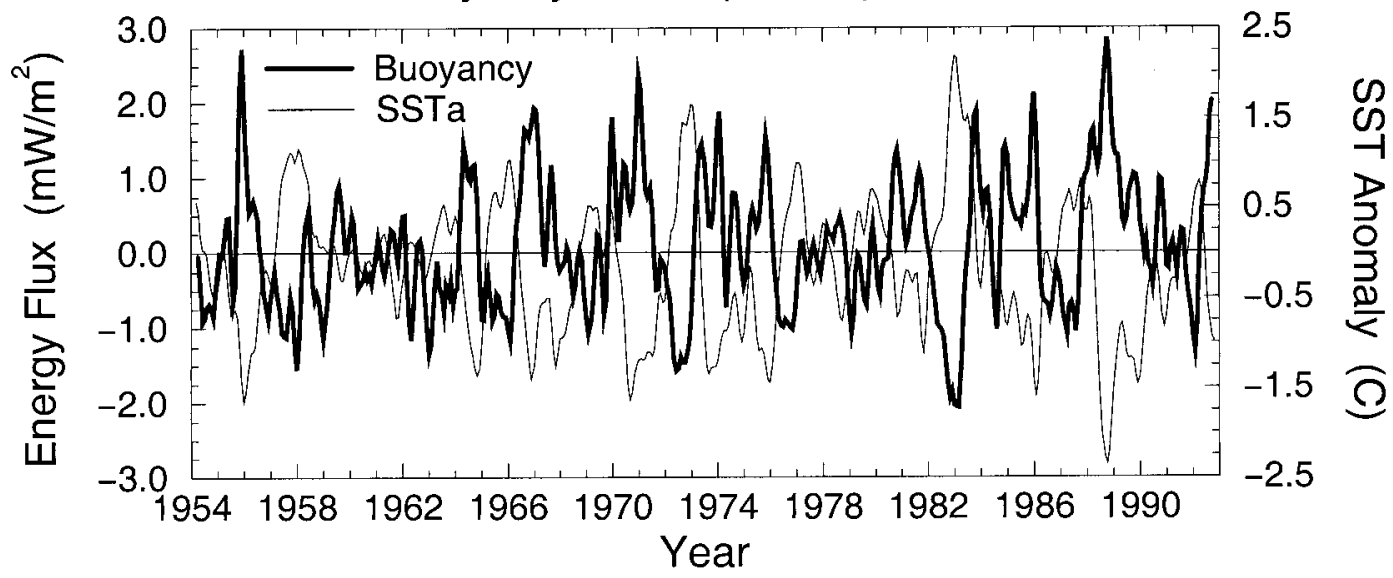

(b)

Upper Oceanic Mass Anomaly (5S-5N) and SSTa (NINO3)

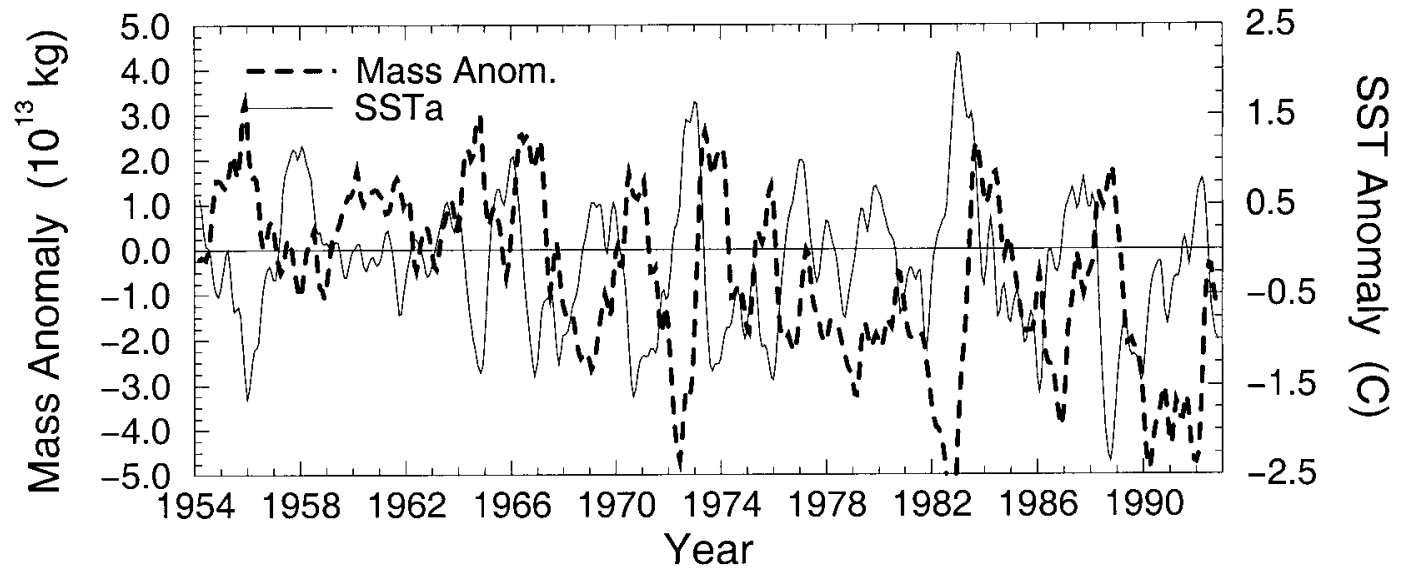

(c)

T-lag Correlation

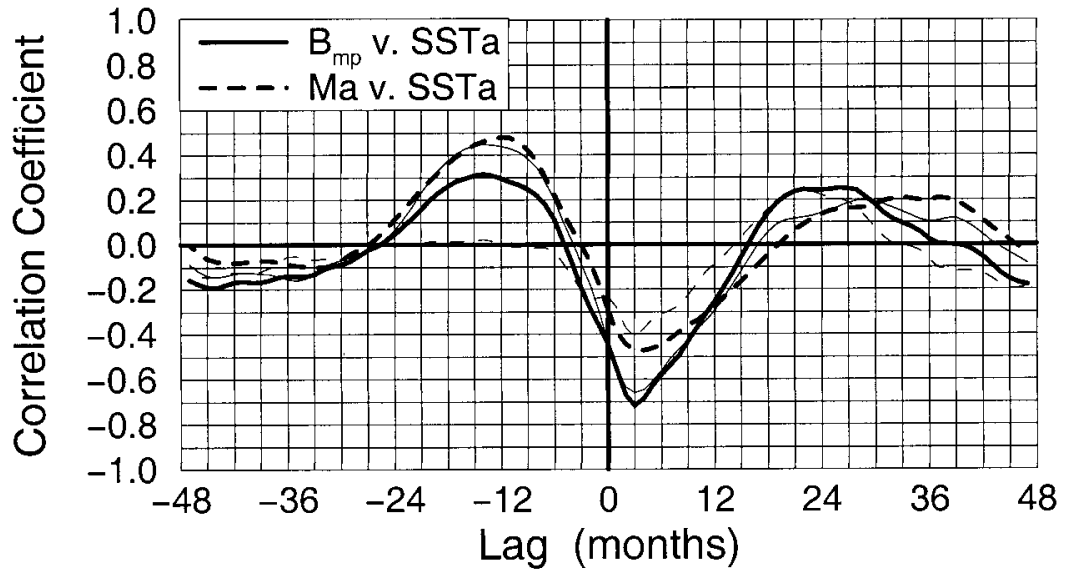

FIG. 7. Mean perturbation buoyancy power $B_{\mathrm{mp}}$ averaged over equatorial Pacific Ocean $\left(5^{\circ} \mathrm{S}-5^{\circ} \mathrm{N} ; 150^{\circ} \mathrm{E}-100^{\circ} \mathrm{W} ; 30-\right.$ $280 \mathrm{~m}$ ), and SST anomaly averaged over Niño-3 region $\left(5^{\circ} \mathrm{S}-5^{\circ} \mathrm{N} ; 150^{\circ}-90^{\circ} \mathrm{W}\right)$. (b) Anomalous mass $(\rho=-\alpha T+\beta S)$ integrated over equatorial Pacific Ocean $\left(5^{\circ} \mathrm{S}-5^{\circ} \mathrm{N} ; 150^{\circ} \mathrm{E}-100^{\circ} \mathrm{W} ; 30-280 \mathrm{~m}\right)$, and SST anomaly averaged over Niño-3 region $\left(5^{\circ} \mathrm{S}-5^{\circ} \mathrm{N} ; 150^{\circ}-90^{\circ} \mathrm{W}\right)$. (c) Time-lag correlations between SSTa and $A_{\mathrm{mp}}$, and SSTa and near-equatorial mass anomaly. SSTa lags the other quantities for positive lag values. Also shown are the time-lag correlations between SSTa and the two terms that compose $B_{\mathrm{mp}}: g h^{\prime} \bar{w}$ (light solid line) and $g \bar{h} w^{\prime}$ (light dashed line). 


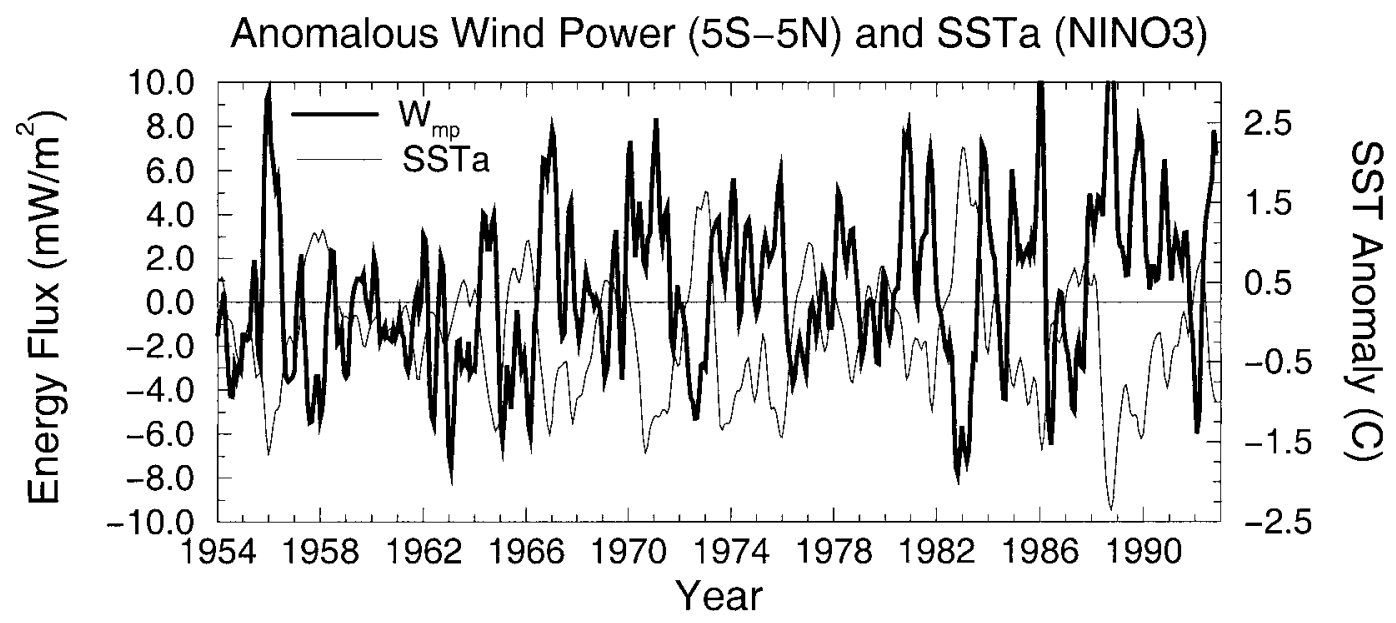

Anomalous Zonal Wind Stress (5S-5N) and SSTa (NINO3)

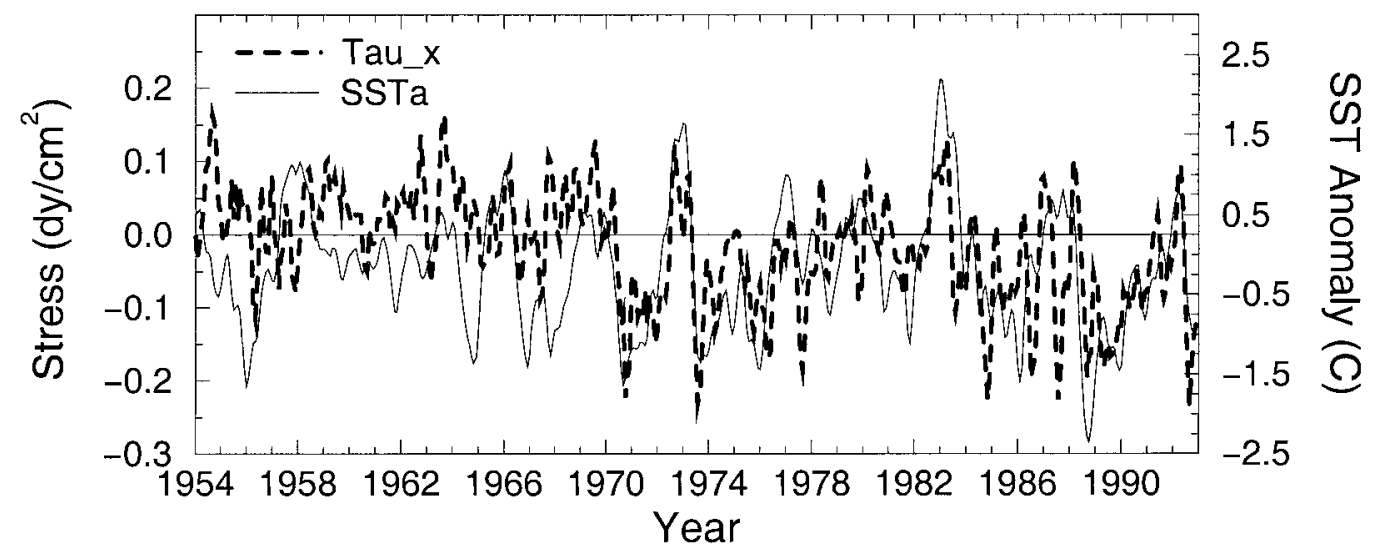

T-lag Correlation

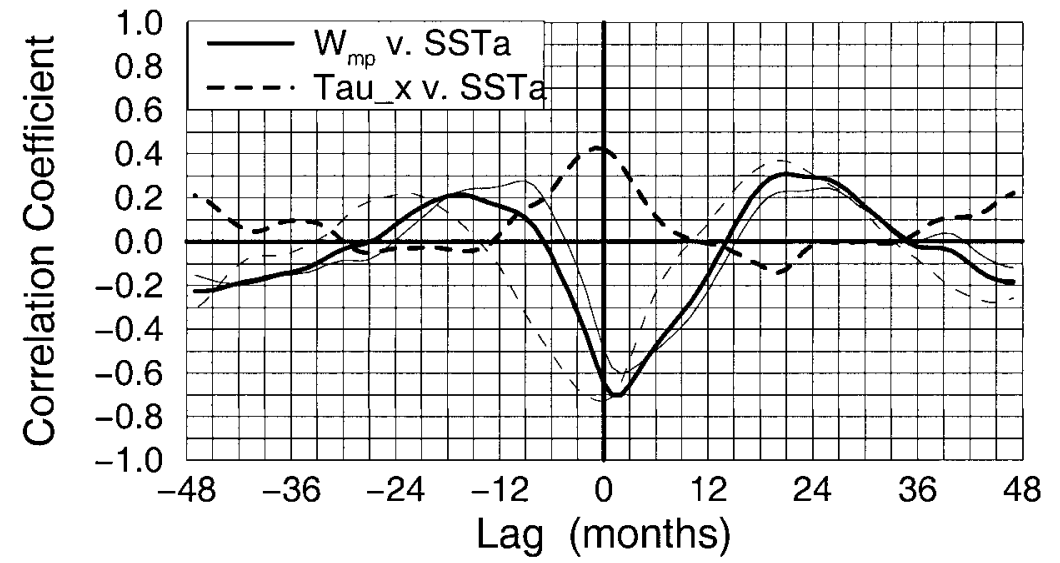

FIG. 8. (a) Mean perturbation wind power $W_{\text {mp }}$ averaged over equatorial Pacific Ocean $\left(5^{\circ} \mathrm{S}-5^{\circ} \mathrm{N} ; 150^{\circ} \mathrm{E}-100^{\circ} \mathrm{W}\right.$; $0-280 \mathrm{~m})$, and SST anomaly averaged over Niño-3 region $\left(5^{\circ} \mathrm{S}-5^{\circ} \mathrm{N} ; 150^{\circ}-90^{\circ} \mathrm{W}\right)$. (b) Anomalous zonal wind stress averaged over equatorial Pacific Ocean $\left(5^{\circ} \mathrm{S}-5^{\circ} \mathrm{N} ; 150^{\circ} \mathrm{E}-100^{\circ} \mathrm{W}\right)$, and SST anomaly averaged over Niño- 3 region $\left(5^{\circ} \mathrm{S}-\right.$ $5^{\circ} \mathrm{N} ; 150^{\circ}-90^{\circ} \mathrm{W}$ ). (c) Time-lag correlation between SSTa and $W_{\mathrm{mp}}$ and SSTa and $\tau^{x^{\prime}}$. SSTa lags the other quantities for positive lag values. Also shown are the time-lag correlations between SSTa and the two terms that compose $W_{\mathrm{mp}}: u^{\prime} \bar{\tau}^{x}$ (light solid line) and $\bar{u} \tau^{x^{\prime}}$ (light dashed line). 

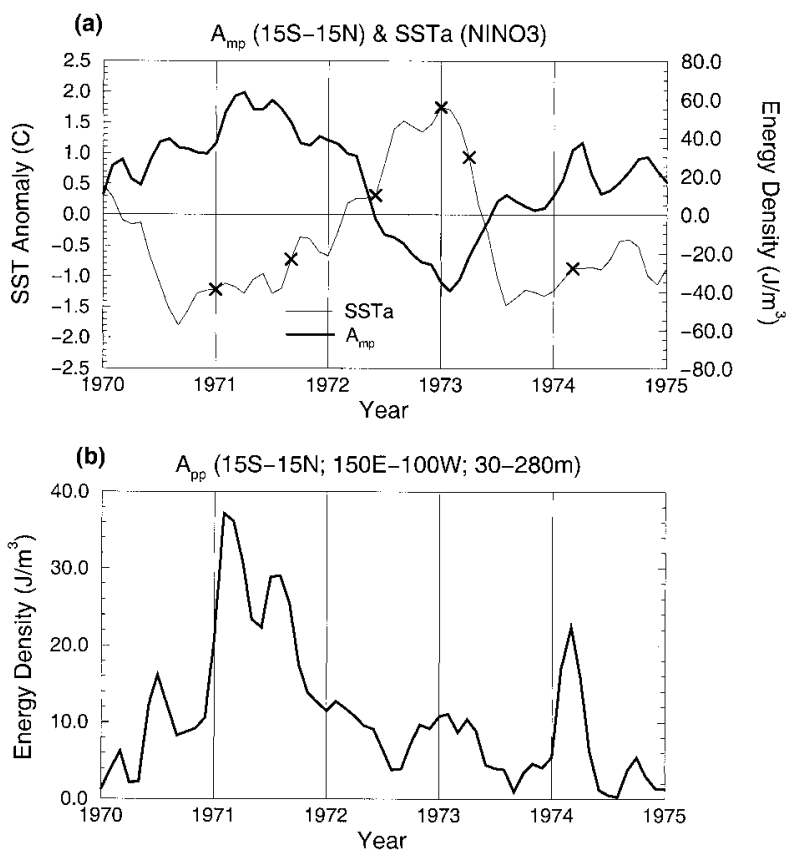

FIG. 9. (a) $A_{\mathrm{mp}} \propto \bar{h} h^{\prime}$ averaged over tropical Pacific subsurface ocean $\left(15^{\circ} \mathrm{S}-15^{\circ} \mathrm{N} ; 150^{\circ} \mathrm{E}-100^{\circ} \mathrm{W} ; 30-280 \mathrm{~m}\right)$, and SST anomaly averaged over Niño-3 region. (b) Perturbation APE density averaged over subsurface tropical Pacific $\left(15^{\circ} \mathrm{S}-15^{\circ} \mathrm{N} ; 150^{\circ} \mathrm{E}-100^{\circ} \mathrm{W} ; 30-280 \mathrm{~m}\right)$.

justment process depicted in Fig. 11. However, when the anomalous wind forcing is strong, $\bar{h} w^{\prime}$ will contribute substantially; because of the typical spatial distribution of $B_{\mathrm{pp}}$ seen in Fig. 10, anomalous upwelling will often be generated in areas where mean upwelling is weak (e.g., off equator) or where $\bar{h}$ is large (e.g., eastern equatorial Pacific or off-equatorial western Pacific).

The time series of both the adjustment buoyancy and the wind-driven buoyancy are presented in Fig. 12b for 1970-75. As suggested above, the adjustment buoyancy displays the low-frequency character of slowly adjusting perturbations. Maps of this term through the 1970-75 period (not shown) exhibit strong values usually confined near the equator, where the mean upwelling is strong, and often extending from the date line to the eastern Pacific. Also, the lead time of strongest correlation between $-h^{\prime} \bar{w}$ (Fig. 7c, thin solid line) is 3 months, consistent with equatorial wave theory that predicts a similar timescale for equatorial Kelvin waves to propagate from the western to eastern boundary. Thus, the temporal behavior and spatial structure of the adjustment buoyancy power fit cleanly within the delayed oscillator paradigm, where mass perturbations adjusting from west to east along the equatorial thermocline lead initially to the decay of the current event and eventually to the genesis of the subsequent event. The wind-driven buoyancy acts on a much higher temporal frequency (Fig. 12b) and spatial frequency (not shown), as was the case of the wind-driven perturbations in Fig. 10. During much of the time series, these two terms contribute constructively to $B_{\mathrm{mp}}$. How- ever, as was shown in Fig. 7c (thin dashed line), the winddriven buoyancy generally participates only during the onset and peak of an event, the demise of the event being controlled by the adjustment buoyancy.

The mean perturbation wind power $W_{\mathrm{mp}}$ similarly is comprised of two terms with differing physical interpretations:

$$
W_{\mathrm{mp}} \propto u^{\prime} \bar{\tau}+\bar{u} \tau^{\prime} .
$$

Again, the first term on the right-hand side is associated with oceanic adjustment, and the second term is related to anomalous wind forcing. However, the distinction between these terms is much greater than was the case for $B_{\mathrm{mp}}$. The partitioning of energy between these terms can be used, for example, to assess the importance of adjusting thermocline perturbations relative to importance of intraseasonal ("wind burst") forcing in the onset, growth, or decay of an event. Note, however, that these results are from an ocean simulation forced with monthly mean winds and may not properly account for the energy input due to the higher-frequency coupling between atmosphere and ocean from wind burst forcing.

During the $1970-75$ period, $u^{\prime} \bar{\tau}$ dominates the wind power (Fig. 12a). This is particularly true during the transition and early growth phases of the El Niño and La Niña events, when this term is actually in competition with $\bar{u} \tau^{\prime}$. The anomalous currents associated with the adjusting perturbations (eastward, for deep, downwelling thermocline perturbations) interact with the mean wind stress to change the energetic state of the ocean long before changes in SSTa nullify or reverse the wind stress anomaly. Even though wind bursts of the appropriate sign appear in the time series (Fig. 12), they are sporadic and generate only a small fraction of the change in energy delivered by $u^{\prime} \bar{\tau}$. As with the adjustment buoyancy, the adjustment wind power (Fig. 13 , left) acts on a much larger scale than does $\bar{u} \tau^{\prime}$ (Fig. 13, right), and during the decay phase is focused near the equator. The appearance of anomalous zonal currents due to adjusting thermocline perturbations is also inherent in the delayed oscillator theory; they are the current anomalies of the equatorial waves. Picaut and Delcroix (1995) have also heralded the importance of these currents for shifting the edge of the western Pacific warm pool. However, those discussions neglected the impact of the dynamical air-sea interaction between the current anomalies and mean wind stress that is seen to effect the oceanic energy so strongly.

\section{Summary}

Changes in gravitational available potential energy (APE) dominate the anomalous energy of the tropical Pacific Ocean interannually. Moreover, these changes in APE are highly anticorrelated and in phase with the changes in sea surface temperature used to index El Niño and La Niña [anomalous SST averaged over the Niño-3 region $\left.\left(5^{\circ} \mathrm{S}-5^{\circ} \mathrm{N} ; 150^{\circ}-90^{\circ} \mathrm{W}\right)\right]$. This implies that 
(a)
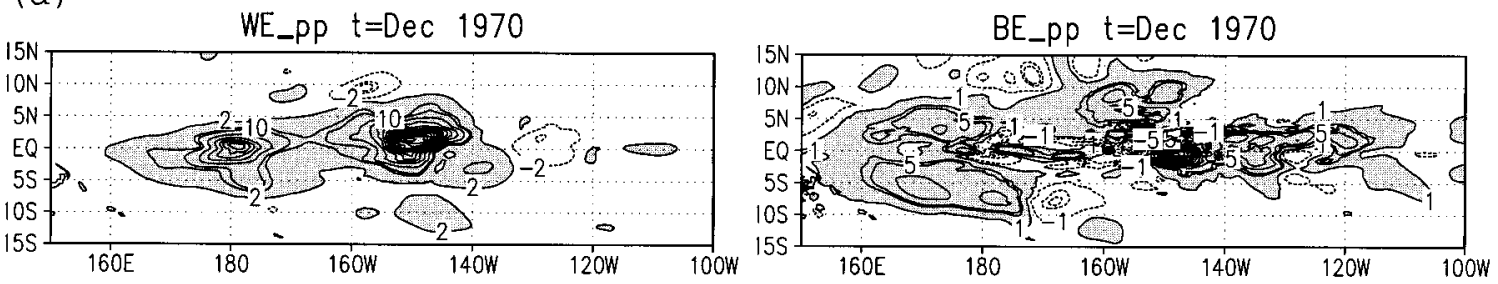

(b)
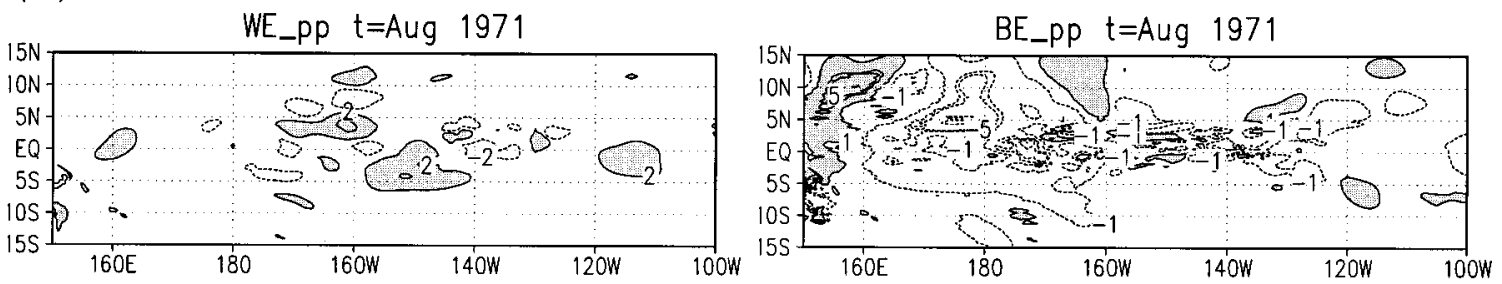

(c)
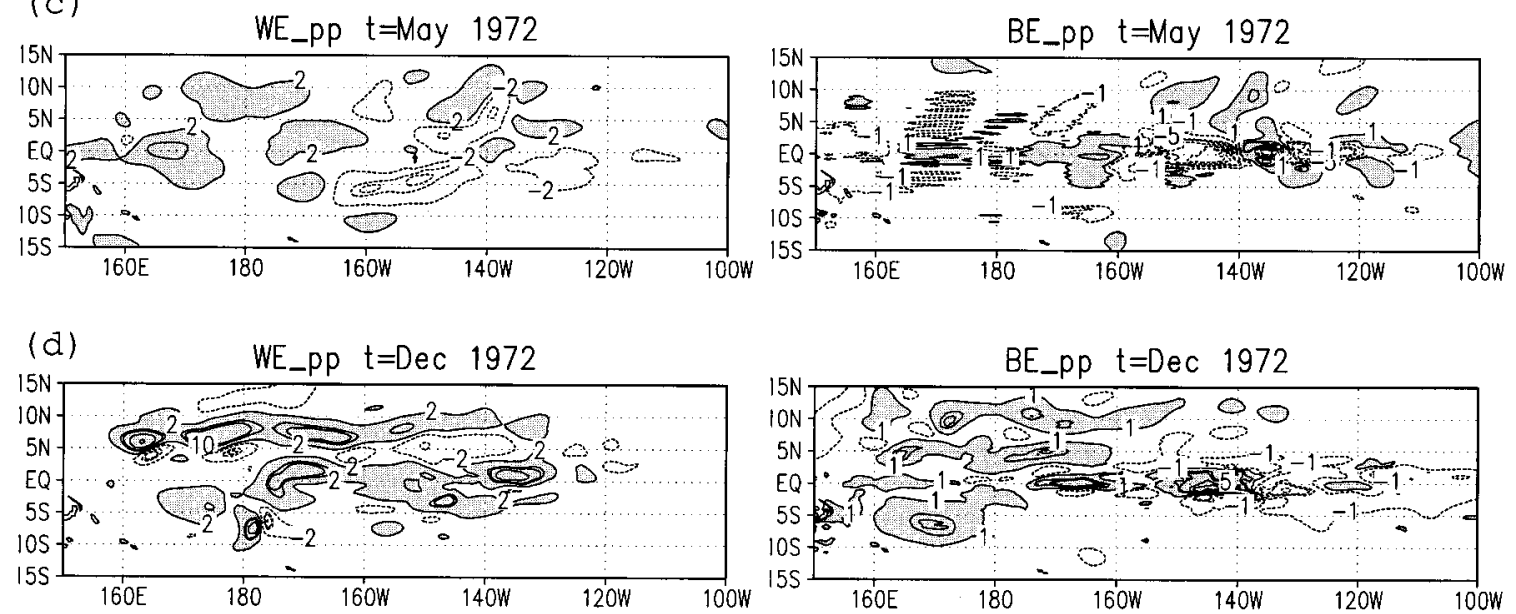

(e)
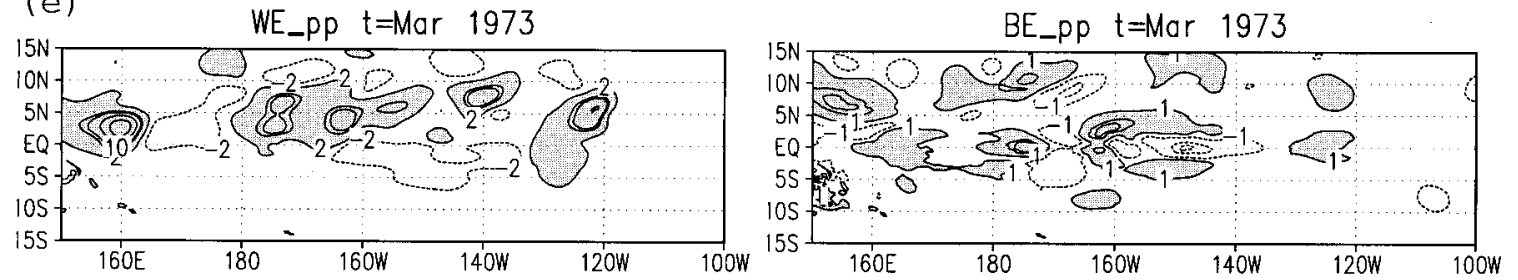

(f)
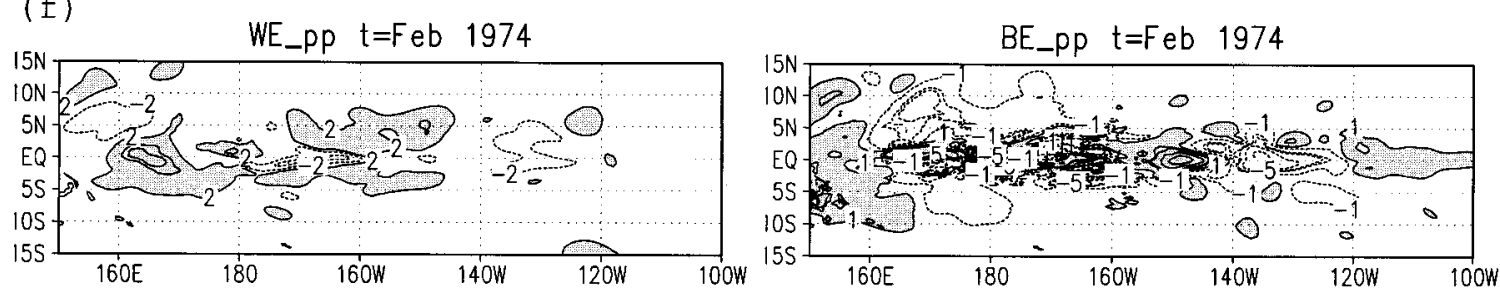

FIG. 10. Perturbation wind power $W_{\mathrm{pp}}$ calculated at surface. Positive values greater than $2 \mathrm{~mW} \mathrm{~m}^{-2}$ are shaded. Contour interval is $8 \mathrm{~mW} \mathrm{~m} \mathrm{~m}^{-2}$, starting at \pm 2 . (right) Perturbation buoyancy power $B_{\mathrm{pp}}$ averaged $30-280 \mathrm{~m}$. Positive values greater than $1 \mathrm{~mW}$ $\mathrm{m}^{-2}$ are shaded. Contour interval is $4 \mathrm{~mW} \mathrm{~m}^{-2}$, starting at \pm 1 . 


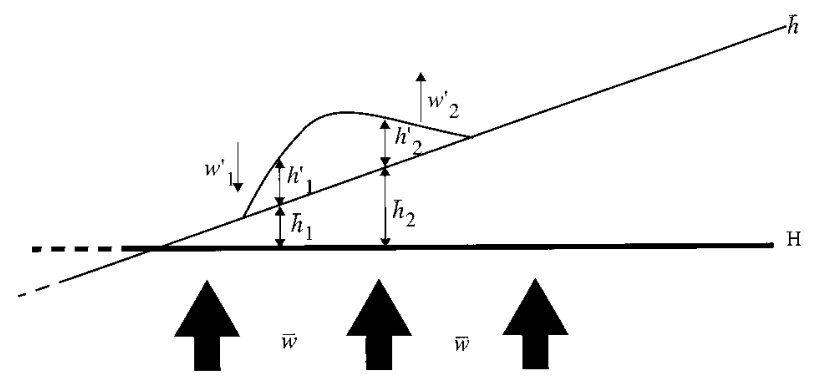

Negative (upward) perturbation to thermocline:

$$
\begin{gathered}
h_{1}^{\prime}=h_{2}^{\prime}=h^{\prime}<0 \\
-w_{1}^{\prime}=w_{2}^{\prime}=w^{\prime}>0 \\
\bar{h}_{2}<\bar{h}_{1}<0
\end{gathered}
$$

Integrating over perturbation:

$$
\begin{aligned}
& -\bar{h} w^{\prime}=-\left(w_{1}^{\prime} h_{1}+w^{\prime}{ }_{2} h_{2}\right)=w^{\prime}\left(h_{1}-\bar{h}_{2}\right)>0 \\
& -h^{\prime} \bar{w}=-\left(h_{1}^{\prime}{ }_{1} \bar{w}+h_{2}{ }_{2} \bar{w}\right)=-2 h^{\prime} \bar{w}>0
\end{aligned}
$$

FIG. 11. Schematic of adjustment buoyancy showing contributions to buoyancy power due to movement of thermocline perturbation on mean state of equatorial Pacific. Mean state is represented as uniform upwelling $\bar{w}$ and a thermocline sloping upward from west to east $\bar{h}$, measured relative to its average depth $H$ (basin assumed to extend farther west than shown). Perturbation is moving eastward.

the ocean gains energy as the air-sea system evolves from El Niño to La Niña and loses energy in going from La Niña to El Niño.

The energy is separated into two parts for this analysis, the perturbation energy and the mean perturbation energy. The perturbation energy equations describe the life cycle-effectively the generation and destruction of perturbations to the mass field (i.e., thermocline perturbations). The mean perturbation energy equations describe how the newly generated perturbations evolve against the mean state. In both cases, the primary balance in the energetics equations yields a simple one-toone relationship between the evolution of APE and the buoyancy power $(-h w)$, which quantifies vertical motion of the mass field. The ultimate energy source comes from the work done by the wind $(u \tau)$ in the kinetic energy equation-which has little effect on the basinwide kinetic energy but, instead, is delivered to buoyancy power, feeding the APE - and the work against pressure gradients by the ageostrophic flow.

The energetics analysis presented for the 1970-75 period, in which the tropical Pacific air-sea system cycled between cold and warm extremes and back again, suggests a strong role for the delayed oscillator mechanism. The results from the energetics support the vision of Suarez and Schopf (1988) and Battisti (1988) (although with slight differences in the details), as follows.

1) Perturbation energy is fed to the ocean during the growth phase of El Niño or La Niña by the perturbation wind power, $u^{\prime} \tau^{\prime}$ (Hirst 1986).

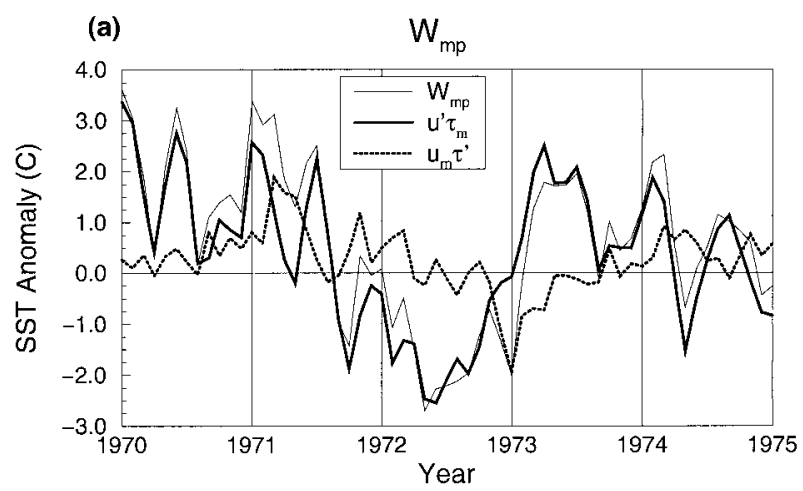

(b)

$\mathrm{B}_{\mathrm{mp}}$

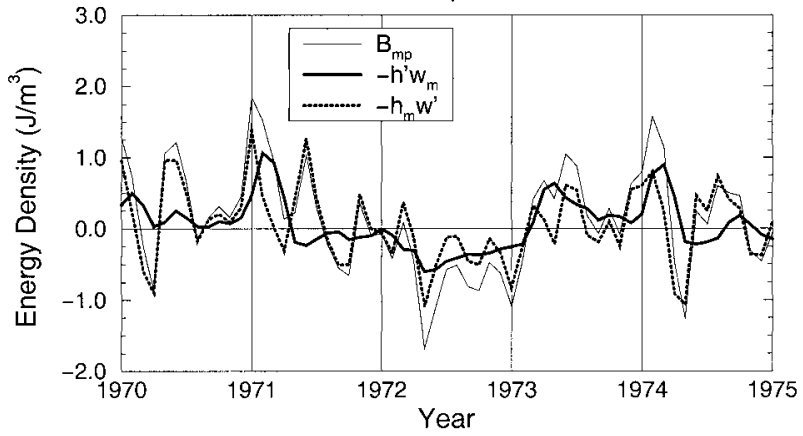

FIG. 12. (a) Decomposition of mean perturbation wind power averaged over tropical Pacific $\left(15^{\circ} \mathrm{S}-15^{\circ} \mathrm{N} ; 150^{\circ} \mathrm{E}-100^{\circ} \mathrm{W}\right) . W_{\mathrm{mp}} \approx \bar{\tau} u^{\prime}$ $+\tau^{\prime} \bar{u}$ (light solid line); $\bar{\tau} u^{\prime}$ : adjustment wind power (heavy solid line); and $\tau^{\prime} \bar{u}$ : mature event wind power (heavy dotted line). (b) Decomposition of mean perturbation buoyancy power averaged over tropical Pacific subsurface ocean $\left(15^{\circ} \mathrm{S}-15^{\circ} \mathrm{N} ; 150^{\circ} \mathrm{E}-100^{\circ} \mathrm{W} ; 30-280\right.$ m). $B_{\mathrm{mp}} \approx-g \bar{h} w^{\prime}-g h^{\prime} \bar{w}$ (light solid line); $-g h^{\prime} \bar{w}$ : adjustment buoyancy power (heavy solid line); and $-g \bar{h} w^{\prime}$ : wind-generated buoyancy power (heavy dotted line).

2) The perturbation wind power is strongest in the central and western tropical Pacific, and generates perturbation buoyancy power on the equator to the east and off the poleward flanks of the wind power to the west.

3) The gained energy subsequently adjusts, against a wind forcing that is neither spatially or temporally coherent, via equatorial wave dynamics. Energy fed into the off-equatorial western Pacific travels to the western boundary where it is channeled into the equatorial wave guide and then propagates along the equator to the eastern Pacific, eroding the current El Niño-La Niña event and often initiating the next one.

The analysis of the mean perturbation energetics of El Niño-La Niña highlights the role of the air-sea interaction occurring while the perturbations are adjusting, before they have begun to influence SST anomalies. The velocity field associated with the adjusting perturbations affects surface currents. The concept of a zonal velocity component to the "delayed" Kelvin wave signal certainly exists in the delayed oscillator theory and has also been suggested to contribute substantially to the change of SST anomalies through zonal advection (Bat- 
(a)

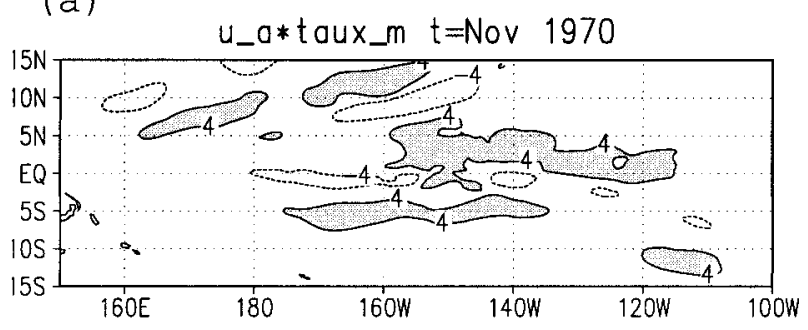

Peak La Nina

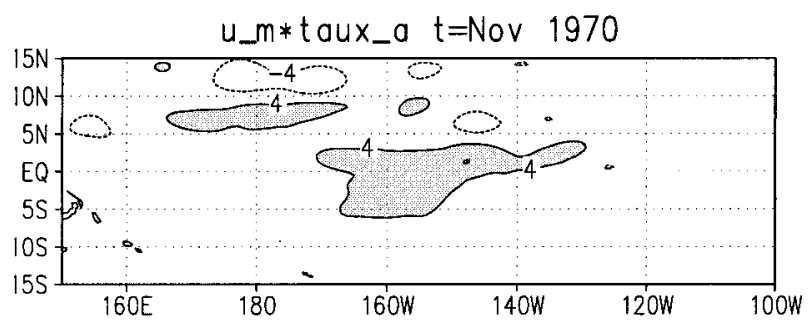

(b)

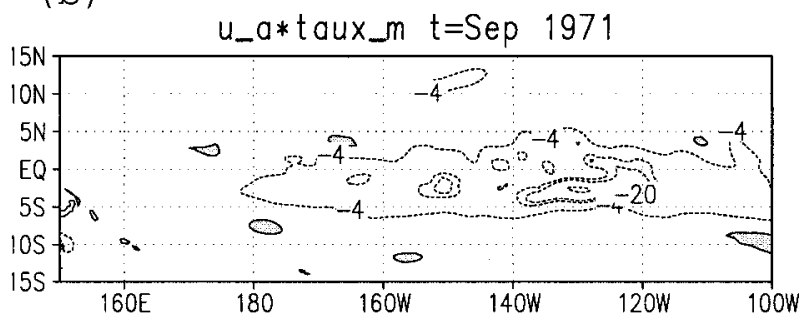

Decay La Nina

(c)

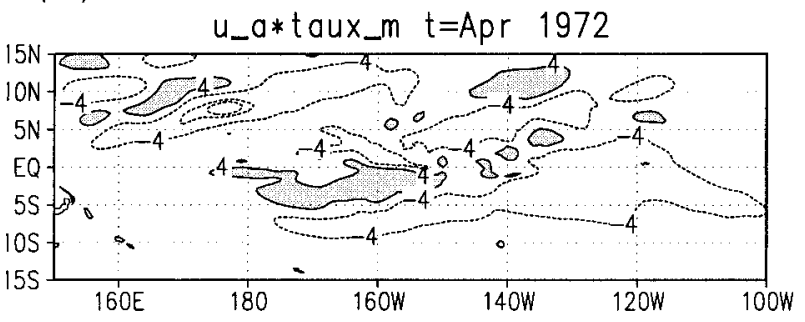

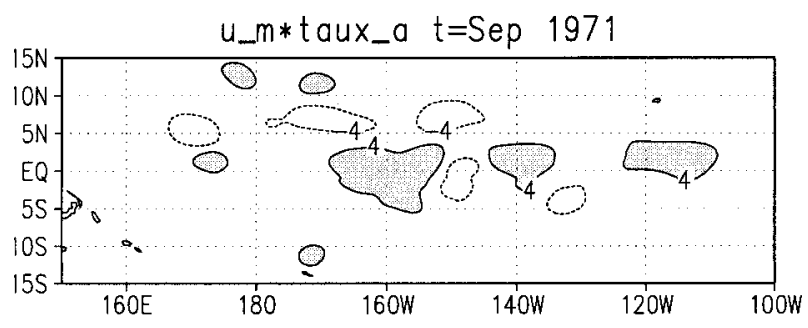

(d)

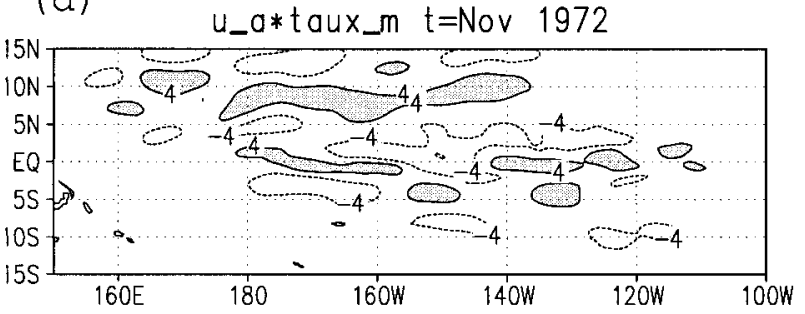

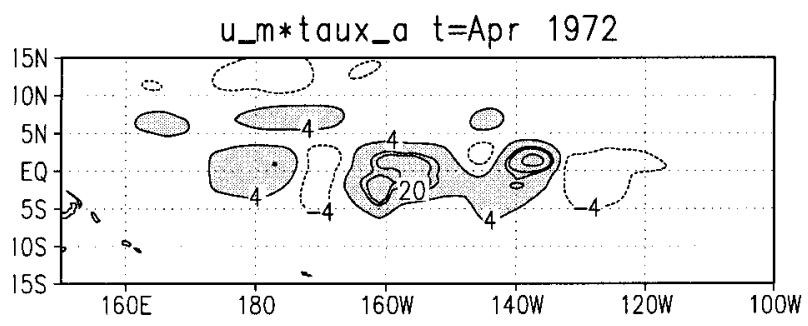

Peak EI Nino

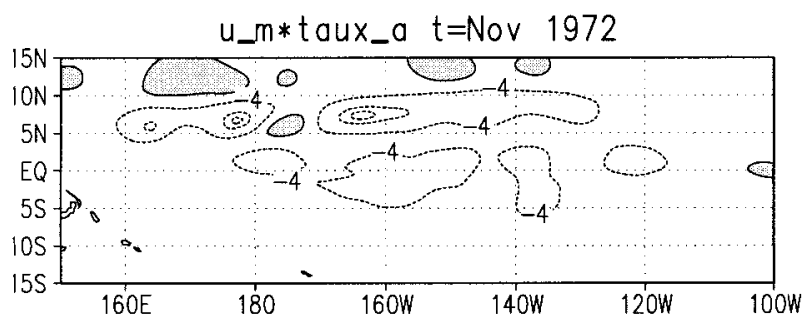

(e)

Decay EI Nino
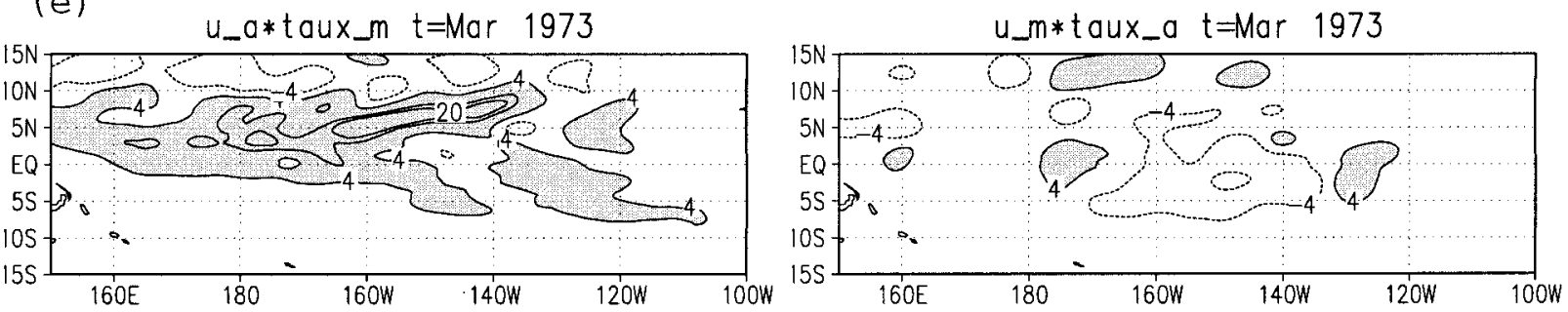

FIG. 13. Maps through La Niña-El Niño cycle for mean anomalous wind power terms. (left) Adjustment wind power $=\bar{\tau} u^{\prime}$. (right) Mature event wind power $=\tau^{\prime} \bar{u}$. Contour interval is $8 \mathrm{~mW} \mathrm{~m}^{-2}$, starting at \pm 4 . Positive values are shaded. 
tisti 1988; Picaut et al. 1997). What the energetics analysis makes more clear is that these delay signals begin to influence conditions in the tropical Pacific, during their adjustment from west to east, generally beginning near the peak of an El Niño or La Niña event.

The signature of this adjustment in the mean perturbation energetics is found in the adjustment wind power $\left(u^{\prime} \bar{\tau}\right)$ as well as the adjustment buoyancy power $\left(h^{\prime} \bar{w}\right)$ and is generally coherent from peak La Niña to peak El Niño and from peak El Niño to peak La Niña (Fig. 12). The observational measurements from TOGATAO already exist for real-time monitoring of the adjustment wind power, which at the very least, may serve as a useful predictor of event transition. It may also prove useful in the debate over which process dominates event initiation: deterministic or stochastic forcing. Note that to evaluate properly the relative importance of stochastic processes, daily or at least pentad data should be used in order to resolve the higher-frequency coupling between atmosphere and ocean.

During the sequence of El Niño and La Niña events of 1970-75, the tropical Pacific appears to be largely deterministic in our simulation, although higher-frequency (i.e., stochastic) behavior is also present. During other periods, stochastic forcing may play a more important role. Two other periods, 1963-67 and 1980-84 (not shown), have been analyzed using energetics, and the results presented herein apply to them as well. This approach has not yet been applied to the unusual period of the early 1990s (Goddard and Graham 1997) nor to the recent "El Niño of the century" for which westerly wind bursts have been implicated as playing a vital role (McPhaden 1999).

Air-sea interaction associated with El Niño and La Niña is intimately related to the air-sea interaction responsible for the mean state of the tropical Pacific. The mean state plays a critical, but implicit, role in conceptual models such as the delayed oscillator. In this study the contribution of the mean state was made explicit. Indeed, examination of the energetics involving interaction between the mean atmospheric winds and anomalous ocean currents uncovers a dynamic air-sea coupling that significantly influences the variability, particularly during the transition between events. Appreciation of this mean perturbation coupling may be used to monitor future variability or to mediate the debate over the relative influences of deterministic and stochastic forcing in initiating El Niño and La Niña events. It may even be used to understand how lower-frequency changes in the mean state might effect the character of El Niño and La Niña events such as those in the 1990s.
Acknowledgments. The authors thank L. Rothstein and another anonymous reviewer for their thoughtful and insightful comments on an earlier draft of this manuscript. We are also grateful for thought-provoking conversations with K. Bryan, N. Mantua, K. Miyakoda, J. D. Neelin, and A. Oort. This work was funded by a NASA Global Change Research Fellowship Grant NGT-30197, and also NA86GP0338(343-6083) and NA56GP0226(343-6100).

\section{APPENDIX}

\section{Energy Equations}

The energy equations used for this study are derived starting from the primitive form of the momentum and thermodynamic equations for a Boussinesq, hydrostatic, and incompressible fluid. These equations are discussed by Bryan (1969) for the ocean GCM used here.

\section{a. Kinetic energy}

The KE equation is obtained by taking the inner product of the three-dimensional momentum equations and velocity vector, $(D \mathbf{u} / D t) \cdot \mathbf{u}$. The resulting equation, written in flux form, where $K$ represents KE, is

$$
\begin{aligned}
K_{t}= & -\boldsymbol{\nabla} \cdot(\mathbf{u} K)-\boldsymbol{\nabla} \cdot(\mathbf{u} p)-\rho g w+\kappa_{M H} K_{x x} \\
& +\left(\kappa_{M H} K_{y}\right)_{y}-\rho_{o} \kappa_{M H}\left(\mathbf{v}_{x} \cdot \mathbf{v}_{x}+\mathbf{v}_{y} \cdot \mathbf{v}_{y}\right)+\left(\kappa_{M V} K_{z}\right)_{z} \\
& -\rho_{o} \kappa_{M V}\left(\mathbf{v}_{z} \cdot \mathbf{v}_{z}\right),
\end{aligned}
$$

where, because of the hydrostatic approximation, only the horizontal velocities contribute to $\mathrm{KE}$ [i.e., $K=$ $\left.\left(\rho_{o} / 2\right)\left(u^{2}+v^{2}\right)\right]$. All variables have their usual meaning: $\mathbf{u}=(u, v, w)$ is the full oceanic velocity field; $\mathbf{v}=(u, v)$ is the two-dimensional horizontal velocity; $p$ and $\rho$ are the three-dimensional pressure and density fields, respectively; $\rho_{o}$ is the mean background density; and $g$ is gravity. Subscripts indicate differentiation with respect to space $[(x, y, z)=$ zonal, meridional, vertical $]$ or time $(t)$. All prescribed and parameterized values are given in Goddard (1995).

The horizontally averaged, time mean portion of the density and pressure fields is in hydrostatic balance. Thus,

$$
-\boldsymbol{\nabla} \cdot(\mathbf{u} p)-\rho g w=-\boldsymbol{\nabla} \cdot\left[\mathbf{u}\left(\tilde{p}+p_{s}\right)\right]-\tilde{\rho} g w,
$$

where the $(\sim)$ signifies deviation from the horizontally averaged field, and $p_{s}$ is the surface air pressure.

Substituting (A2) into (A1) and integrating them over a fixed volume in the ocean, the final form of the full kinetic energy equation appears as

$$
\begin{aligned}
\frac{\partial}{\partial t} \iiint K d V= & -\oint K \mathbf{u} \cdot \hat{n} d \sigma-\oint\left(\tilde{p}+p_{s}\right) \mathbf{u} \cdot \hat{n} d \sigma-g \iiint \tilde{\rho} w d V \\
& +\iint_{z=0} \mathbf{v} \cdot \boldsymbol{\tau}_{o} d \sigma \rho_{o}-\iiint \kappa_{M V}\left(\mathbf{u}_{z} \cdot \mathbf{u}_{z}\right) d V \rho_{o}-\iiint \kappa_{M H}\left[\left(\mathbf{u}_{x} \cdot \mathbf{u}_{x}\right)+\left(\mathbf{u}_{y} \cdot \mathbf{u}_{y}\right)\right] d V .
\end{aligned}
$$


Unit surface area is denoted by $d \sigma$, and $\hat{n}$ points out of the volume. The diffusion of energy through the bottom of the volume is neglected because of the weak vertical shear of the horizontal currents at depths much below the thermocline. The terms on the right-hand side of this equation are identified as

1) $\oint K \mathbf{u} \cdot \hat{n} d \sigma \equiv$ the advection of kinetic energy through the "walls" of the volume;

2) $\oint\left(\tilde{p}+p_{s}\right) \mathbf{u} \cdot \hat{n} d \sigma \equiv$ the change of kinetic energy due to work done against pressure gradients by the ageostrophic flow;

3) $g \iiint \tilde{\rho} w d V \equiv$ the kinetic energy lost to vertical movement of the mass field (buoyancy power);

4) $\iint_{z=0} \mathbf{v} \cdot \boldsymbol{\tau}_{o} d \sigma \equiv$ the source of kinetic energy due to the wind stress $\left(\tau_{o}\right)$ acting on the surface currents; and,

5) and 6) $\rho_{o} \iiint \kappa_{M H}\left[\left(\mathbf{u}_{x} \cdot \mathbf{u}_{x}\right)+\left(\mathbf{u}_{y} \cdot \mathbf{u}_{y}\right)\right]+\kappa_{M V}\left(\mathbf{u}_{z} \cdot \mathbf{u}_{z}\right)$ $d V \equiv$ energy losses within the volume from work done by stresses due to horizontal and vertical shears in the flow, respectively.

\section{b. Available potential energy}

The derivation of available potential energy (APE), specifically the available gravitational potential energy, proceeds from the equation for density conservation:

$$
\begin{aligned}
\tilde{\rho}_{t} & +\mathbf{u} \cdot \boldsymbol{\nabla} \tilde{\boldsymbol{\rho}}+w \hat{\rho}_{z} \\
& =\kappa_{T H}\left(\tilde{\rho}_{x x}+\tilde{\rho}_{y y}\right)+\left[\kappa_{T V}\left(\hat{\rho}_{z}+\tilde{\rho}_{z}\right)\right]_{z}+Q_{\rho} .
\end{aligned}
$$

The variable $\hat{\rho}_{z}$ is the vertical gradient of potential density as opposed to in situ density (Oort et al. 1989; Neumann and Pierson 1966), where $\hat{\rho}$ is the time mean potential density horizontally averaged over the analysis region; and $\tilde{\rho}$ contains the spatially and temporally varying components of the density field. The source term $Q$ encompasses both the thermal and salinity fluxes impacting the density field.
The OGCM used here does not calculate density as a prognostic tracer; rather it calculates the temperature and salinity fields using the tracer conservation equation, calculating the density only when needed (e.g., for the Richardson number-dependent mixing coefficients). This model approximates density from a third-order polynomial involving temperature, salinity, and depth; thus density is not necessarily conserved in the GCM, even though the temperature and salinity are.

The density field here is approximated as a linear combination of $T$ and $S$, and so will be conserved:

$$
\rho=\rho_{o}-\alpha T+\beta S .
$$

The values of the expansion coefficients are given by

$$
\begin{aligned}
\alpha & =2.60 \times 10^{-4} \mathrm{~g} \mathrm{~cm}^{-3}\left({ }^{\circ} \mathrm{C}\right)^{-1} ; \\
\beta & =7.65 \times 10^{-4} \mathrm{~g} \mathrm{~cm}^{-3} \mathrm{ppt}^{-1},
\end{aligned}
$$

based on values supplied by Gill (1980). This linear representation for density has shown to be a good firstorder approximation for the range of temperatures and salinities of the world ocean (Bryan and Cox 1972), and particularly so for the even narrower range of temperatures and salinities of the tropical upper ocean.

The APE equation is derived to leading order by ignoring nonlinear changes in temperature and salinity. According to Reid et al. (1981), "the collective effects of these [neglected] terms in an [global] oceanwide sense is that they contribute $<10 \%$ to the total APE," and again, the narrow range of $T$ and $S$ of the tropical Pacific upper ocean yields an even smaller estimated error for both the mean and interannual conditions.

Equation (A4) is then multiplied through by $-g \tilde{\rho} / \hat{\rho}_{z}$, where the "stability-like" weighting has been chosen to illuminate the conversion between KE and APE. The equation for the APE, after integrating over a large oceanic volume, is then

$$
\begin{aligned}
\frac{\partial}{\partial t} \iiint A d V= & -\oint(\mathbf{u} A) \cdot \hat{n} d \sigma+g \iiint \tilde{\rho} w d V+\iiint A w\left(\frac{\hat{\rho}_{z z}}{\hat{\rho}_{z}^{2}}\right) d V+\oint \kappa_{T H} \boldsymbol{\nabla} A \cdot(\hat{i}, \hat{j}) d \sigma \\
& \left.-\iiint \frac{\kappa_{T H}}{\mathcal{N}^{2}}\left[\left(\tilde{\rho}_{x}\right)^{2}+\left(\tilde{\rho}_{y}\right)^{2}\right] d V+\iiint \int \frac{\tilde{\rho}}{\mathcal{N}^{2}}\left(\kappa_{T V} \rho_{z}\right)_{z}\right] d V+\iiint\left(\frac{\tilde{\rho}}{\mathcal{N}^{2}} Q_{\rho}\right) d V
\end{aligned}
$$

where the APE is defined (Oort et al. 1989) as

$$
A=-\frac{g}{2 \hat{\rho}_{z}} \tilde{\rho}^{2}=\frac{1}{2} \frac{\tilde{\rho}^{2}}{\mathcal{N}^{2}},
$$

and $\mathcal{N}^{2}=-\hat{\rho}_{z} / g$ is the depth-dependent stability factor.

The terms on the right-hand side of the APE equation can be identified as

1) $\oint(\mathbf{u} A) \cdot \hat{n} d \sigma \equiv$ the advection of APE through the walls of the volume;
2) $g \iiint \tilde{\rho} w d V \equiv$ vertical motion of the mass field (buoyancy power);

3) $\iiint A w\left(\hat{\rho}_{z z} / \hat{\rho}_{z}^{2}\right) d V \equiv$ the apparent source or sink due to shear in the stability profile;

4) $\oint \kappa_{T H} \nabla A \cdot(\hat{\imath}, \hat{j}) d \sigma \equiv$ the horizontal diffusion of APE through the walls of the volume; and

5) $\iiint\left(\kappa_{T H} / \mathcal{N}^{2}\right)\left[\left(\tilde{\rho}_{x}\right)^{2}+\left(\tilde{\rho}_{y}\right)^{2}\right] d V \equiv$ the dissipation of APE within the volume due to horizontal density gradients. 
6) $\iiint\left[\left(\tilde{\rho} / \mathcal{N}^{2}\right)\left(\kappa_{T V} \rho_{z}\right)_{z}\right] d V \equiv$ the vertical diffusion and dissipation of APE. They are not separated since the vertical dependence of the diffusivity coefficient and the stability lead to a long and messy form. As with the KE, the diffusion/dissipation terms are smaller and more noisy than other terms in the balance, so they are lumped into a single term.

7) $\iiint\left[\left(\tilde{\rho} / \mathcal{N}^{2}\right) Q_{\rho}\right] d V \equiv$ the change in APE due to surface fluxes of density connected with thermal and fresh water sources (i.e., $Q_{\rho}=-\alpha Q_{\text {heat }}+\beta Q_{\text {salt }}$ ).

As described by Lorenz (1955), the concept of APE refers to energy that may be stored or extracted by a redistribution of the mass field, which implies that an analysis of APE should be applied to a fixed mass of fluid. In the preceding derivation of APE, three approximations have been made concerning the ocean's mass field. First, density is a linear combination of temperature and salinity. Second, mass is conserved in our "open-boundary" volume. And third, APE can be described by its leading-order Taylor-expanded term (Reid et al. 1981). Each of the three assumptions is valid for our data to within a few percent of the total energy seasonally and interannually.

Using this formulation for APE, the goal is not to give an exact value in a localized sense, but rather to see how the APE changes in a more regional, basinwide sense. The simplifications allow the APE equation to be matched against the KE equation in a straightforward way in order to see the dynamical forcing of the APE directly. If one desires more precise numbers for the energy densities at particular times and places, these can be retrieved by more exact formulations later.

\section{EXCLUSION OF THE MIXED LAYER}

Since the concept of gravitational APE rests on the possible adiabatic redistribution of mass, the mixed layer, where the fluid is well mixed and changes in energy are primarily diabatic, should be excluded. The stability is much weaker near the surface, and horizontal gradients in density are effectively nonexistent (Rudnick and Ferrari 1999); thus large-scale gravitational processes are unimportant to interannual variability in the mixed layer. However, due to the vanishing vertical density gradient and the present formulation for APE [Eq. (A9)], surface processes may be weighted more heavily in the volume-integrated APE equation than are subsurface ones. If the mixed layer were to be included in the volume integral, the surface would dominate, and the APE anomaly would measure merely the strength of the SST anomaly. In the real world, a conversion between potential and internal forms of energy would occur such that the energy in the mixed layer is primarily internal energy (IE; measuring temperature changes). The conversion between APE and IE is not possible, however, in the hydrostatic and Boussinesq OGCM used in this study.
To isolate the dynamically forced and physically meaningful portion of the upper-ocean APE, the mixed layer is discarded for volume integrations of APE. Although the actual mixed layer, generally defined as $T_{\text {sub }}$ $=T_{\text {srf }}-0.5^{\circ} \mathrm{C}$, has significant spatial variation in the Tropics (Levitus 1982), a constant value, based on the model's stability profile, is adequate for this analysis. The mixed layer depth here is taken as $30 \mathrm{~m}$, based on the tenfold increase in the potential density gradient with respect to the surface (not shown).

\section{REFERENCES}

Anderson, D. L. T., and A. M. Moore, 1989: Initialization of equatorial waves in ocean models. J. Phys. Oceanogr., 19, 116-121.

Battisti, D. S., 1988: Dynamics and thermodynamics of a warming event in a coupled tropical atmosphere-ocean model. J. Atmos. Sci., 45, 2889-2919.

— atmosphere/ocean system: Influence of the basic state, ocean geometry, and nonlinearity. J. Atmos. Sci., 46, 1687-1712.

Bryan, K., 1969: A numerical method for the study of the world ocean. J. Comput. Phys., 4, 347-376.

—, and M. D. Cox, 1967: A numerical investigation of the ocean general circulation. Tellus, 19, 54-80.

— models of ocean circulation. J. Phys. Oceanogr., 2, 510-514.

Cane, M. A., and S. E. Zebiak, 1985: A theory for El Niño and the Southern Oscillation. Science, 228, 1085-1087.

Cox, M. D., 1984: A primitive equation, 3-dimensional model of the ocean. GFDL Tech. Rep. 1, 140 pp. [Available from Geophysical Fluid Dynamics Laboratory, Princeton, NJ 08542.]

Dijkstra, H. A., and J. D. Neelin, 1995: Ocean-atmosphere interaction and the tropical climatology. Part II: Why the Pacific cold tongue is in the east. J. Climate, 8, 1343-1359.

Evans, M., A. Kaplan, and M. Cane, 1998: Optimal sites for coralbased reconstruction of sea surface temperature. Paleoceanography, 13, 502-516.

Gill, A. E., 1980: Some simple solutions for heat-induced tropical circulation. Quart. J. Roy. Meteor. Soc., 106, 447-462.

_ 1983: An estimation of sea-level and surface-current anomalies during the $1972 \mathrm{El}$ Niño and subsequent thermal effects. J. Phys. Oceanogr., 13, 586-606.

Goddard, L., 1995: The energetics of interannual variability in the tropical Pacific Ocean. Ph.D. thesis, Princeton University, 210 pp. [Available from Dept. of Atmospheric and Oceanic Sciences, Princeton University, Princeton, NJ 08542.]

_ Res., 102, $10423-10436$.

Hirst, A. C., 1986: Unstable and damped equatorial modes in simple coupled ocean-atmosphere models. J. Atmos. Sci., 43, 606-630.

Jiang, M., J. D. Neelin, and M. Ghil, 1995: Quasi-quadrennial and quasi-biennial variability in COADS equatorial Pacific sea surface temperature and winds. Climate Dyn., 12, 101-112.

Kessler, W. S., M. J. McPhaden, and K. M. Weickmann, 1995: Forcing of intraseasonal Kelvin waves in the equatorial Pacific. J. Geophys. Res., 100, $10613-10631$.

Levitus, S., 1982: Climatological Atlas of the World Ocean. National Oceanic and Atmospheric Administration, NOAA Professional Paper 13, 173 pp. and 17 microfiche.

Li, B., and A. J. Clarke, 1994: An examination of some ENSO mechanisms using intrannual sea level at the eastern and western equatorial boundaries and the zonally averaged equatorial wind. J. Phys. Oceanogr., 24, 681-690.

Lorenz, E. N., 1955: Available potential energy and the maintenance of the general circulation. Tellus, 7, 157-167.

Mantua, N. J., and D. S. Battisti, 1994: Evidence for the delayed oscillator mechanism for ENSO: The "observed" oceanic 
Kelvin mode in the far western Pacific. J. Phys. Oceanogr., 24, 691-699.

McCreary, J. P., 1978: Eastern tropical ocean response to changing wind systems. Review of Papers of Equatorial OceanographyFINE Workshop Proceedings, Nova N.Y.I.T. University Press, chapter 7.

McPhaden, M. J., 1999: Genesis and evolution of the 1997-98 El Niño. Science, 283, 950-954.

— and Coauthors, 1998: The Tropical Ocean-Global Atmosphere observing system: A decade of progress. J. Geophys. Res., 103, 14 169-14 240.

Neelin, J. D., 1991: The slow sea surface temperature mode and the fast-wave limit: Analytical theory for tropical interannual oscillations and experiments in a hybrid coupled model. J. Atmos. Sci., 48, 584-606.

— D. S. Battisti, A. C. Hirst, F.-F. Jin, Y. Wakata, and S. E. Zebiak, 1998: ENSO theory. J. Geophys. Res., 103, 14 261-14 290

Neumann, G., and W. J. Pierson Jr., 1966: Principles of Physical Oceanography. Prentice-Hall, 545 pp.

Oort, A. H., S. C. Ascher, S. Levitus, and J. P. Peixoto, 1989: New estimates of the available potential energy in the world ocean. J. Geophys. Res., 94, 3187-3200.

Pacanowski, R. C., 1987: Effect of equatorial currents on surface stress. J. Phys. Oceanogr., 17, 833-838.

— ing in numerical models of tropical oceans. J. Phys. Oceanogr., 11, 1443-1451.

— , K. Dixon, and A. Rosati, 1991: The G.F.D.L. modular ocean model users guide. GFDL Tech. Rep. 2. [Available from Geophysical Fluid Dynamics Laboratory, Princeton, NJ 08542.]

Philander, S. G. H., T. Yamagata, and R. C. Pacanowski, 1984: Unstable air-sea interactions in the Tropics. J. Atmos. Sci., 41, 604613.

_, W. Hurlin, and A. D. Siegel, 1987: A model of the seasonal cycle in the tropical Pacific Ocean. J. Phys. Oceanogr., 17, 19862002.

Picaut, J., and T. Delcroix, 1995: Equatorial wave sequence associated with warm pool displacements during the 1986-1989 El NinoLa Nina. J. Geophys. Res., 100, 18 393-18 408.

— - F. Masia, and Y. du Penhoat, 1997: An advective-reflective conceptual model for the oscillatory nature of ENSO. Science, 277, 663-666.

Rasmusson, E. M., and T. H. Carpenter, 1982: Variations in tropical sea surface temperature and surface wind fields associated with the Southern Oscillation/El Niño. Mon. Wea. Rev., 110, 354384.

Reid, R., B. Elliot, and D. Olson, 1981: Available potential energy: A clarification. J. Phys. Oceanogr., 11, 15-29.

Richardson, P. L., and T. K. McKee, 1984: Average seasonal variation of the Atlantic equatorial currents from historical ship drifts. $J$. Phys. Oceanogr., 14, 1226-1238.

Rosati, A., and K. Miyakoda, 1988: A general circulation model for the upper ocean simulation. J. Phys. Oceanogr., 18, 1601-1626.

Rudnick, D. L., and R. Ferrari, 1999: Compensations of horizontal temperature and salinity gradients in the ocean mixed layer. Science, 283, 526-529.

Schopf, P. S., and M. J. Suarez, 1988: Vacillations in a coupled oceanatmosphere model. J. Atmos. Sci., 45, 549-566.

Slutz, R., S. Lubker, J. Hiscox, S. Woodruff, R. Jenne, D. Joseph, P. Streurer, and J. Elms, 1985: Comprehensive ocean-atmosphere data set: Release 1. NOAA Environmental Research Laboratories Climate Research Program, Boulder, CO.

Suarez, M. J., and P. S. Schopf, 1988: A delayed action oscillator for ENSO. J. Atmos. Sci., 45, 3283-3287.

Wyrtki, K., 1975: El Niño-The dynamic response of the equatorial Pacific Ocean to atmospheric forcing. J. Phys. Oceanogr., 5, $572-584$.

Yamagata, T., 1985: Stability of a simple air-sea coupled model in the tropics. Coupled Ocean-Atmosphere Models, J. Nihoul, Ed., Elsevier Oceanography Series, Vol. 40, Elsevier, 637-657. 